\title{
A Critique of Marriage Within China Through The Lens of Feminism
}

\author{
Xiaoxue Chen
}

A thesis submitted to the Victoria University of Wellington in fulfilment of the requirements for the degree of Master of Design Innovation 



\section{Abstract}

Within the traditional patriarchal ideology in China, feminism is gradually being accepted by the Chinese, especially Chinese women, and has brought benefits to women's liberation today. However, inequality between men and women still exists. There is growing popularity among Chinese women artists to use their artistic status as their weapon to actively and effectively communicate the ideologies of feminism. However, their expression of feminism still mostly manifests through traditional artistic mediums. My research focuses on how wearable technology can depict and criticize gender inequality in Chinese marriage, and promote feminism. The garment design development is based on the results of a study I conducted about the perception of marriage equality in China, which revealed several areas of inequality in marriage. The final garment is designed for presentation, where movement and audience interaction are considered to enhance the opportunities of wearable technology to best communicate aspects of marriage inequality in China. My design research realises how ideologies of feminism, specifically marriage equality in China, might be advocated for through the design of contemporary garments and wearable technology. 



\section{Acknowledgements}

I would like to thank my supervisor Anne Niemetz for her guidance and support to help me to construct my thesis, which also helped me in doing a lot of research. As well as Ben Jack who gave me the technology's guide. I came to know about many new things. I am really thankful to them.

Secondly, I would also like to thank Zara Fong for my garment's model. At the end, I would also like to thank my parents and friends who helped and supported me a lot in finalizing this project within the limited time frame. 


\section{Table of Contents}

1 Introduction

2 The Historical Role of Women in Chinese Culture

$2.1 \quad$ In the ancient times

2.2 The period of Republic of China

2.3 The People's Republic of China- PRC

$2.4 \quad 215 t$ Century

3 Literature Review

3.1 Feminism in China

3.2 Feminist Artwork

3.3 Wearable Technology and Wearable Art

3.4 Precedent Review

$4 \quad$ Method

4.1 Areas where Chinese artists have not explored

4.2 Aims and Objectives

5 Exploration

5.1 Result Questionnaire

5.2 Design Concept

5.3 Design Development 
6 Physical Experiment

6.1 Fabric

6.2 Prototype

7 Technology Experiment

$7.1 \quad$ Input

7.2 Output

$8 \quad$ Final Design

$8.1 \quad$ Zi.Force Design

8.2 Circuit allocation plan

8.3 Zi.Force Photograph Album

9 Discussion and Conclusion

10 References 
Introduction 
"For a thousand years before the establishment of Communism, Chinese family life adhered to Confucian philosophy. Prior to 1949 , marriage had been a private affair between families (Schneider, 2014)." Families usually arranged marriages. Women had a very low status in that period. They could not control their life. Before marriage, they had to obey their father's orders, or their brothers' if their father died. After marriage, they had to obey their husband. In Chinese history, there was a law that was called "Qi chu (七出)". This laid out seven conditions where a husband could divorce his wife. These conditions were all concerned with wife's supposed duties to her husband and family. For example, the husband could divorce his wife if she had no children or became very sick. "Qi chu (七出)" meant that a husband or his family could renounce his wife if she met one of these terms. This system was unfair and oppressed women. "Under Mao's regime, it became a legal status to be conferred or removed through state approval (Schneider, 2014)." The government arranged marriages. As modern China emerged, and the political system constantly reformed, the law did not protect Chinese women's marriage rights well. Chinese women suffered from oppression and exclusion that is ongoing in different forms. In particular, rural women are still severely disadvantaged by their gender.

Even today, the Chinese traditional patriarchal ideology remains heavily ingrained within the culture. Chinese society has not progressed to a point where women and men are equal. With Chinese economic reform and its opening to the outside after 1978, Western culture became influential in Chinese people's life. Western feminism appeared in China. Since then, some female Chinese artists found a way to express their experiences of inequality between men and women. Wearable technology is a modern medium. It is interactive with self-experience or audience. A few of Chinese artists use this to express their work.

My research will focuses on several areas:

1) Identify and discuss gender inequality in Chinese marriage

2) Investigate and analyse Chinese artists that depict feminist narratives of female status

3) Research wearable technology and wearable art

By researching these areas, I will use wearable technology to depict the perceptions Chinese women hold of 21st century marriage. I would like to raise awareness about marriage inequality in China, by creating a garment that invites thinking and discussion on this issue. My garment is based on the results of research. The findings of my research suggest that Chinese single women have not a freedom of marriage in the 21st century. Single women are called "leftover women" in their late 20s. Their parents will pester them about marriage. Parents fear that the daughter's life is unsuccessful if she cannot get married. However, the traditional marriage concepts are not "Leftover Women" want life. Raising a family is not only option for a woman.

My garment will use stretch material to express inequality in Chinese marriage. In the final garment will be documented with photographs and video. I choose video to document the final output because it has most effective that can document the garment's interactions with others. 
The Historical Role of Women in Chinese Culture 
"Family" is a critical concept for Chinese people. Everyone plays a different role in family, such as father, mother, wife, husband and child. Everyone has a responsibility and obligation. The basic family is composed of a man and a woman. However, Chinese marriage is not about two young people coming together. It is not about creating a romantic or sexually compatible union ( $\mathrm{Du}$, 2016). Marriage is the binding of two families. It is the basis of the patriarchal social and hierarchy system, and as such the traditional Chinese family has a lot of gender inequality (Zhou, 2010).

\section{In ancient times}

China has a strong historical and national culture. Throughout the last five thousand years of China's civilization its social foundation has developed and evolved. Confucianism, Taoism and Legalism all played a decisive role that defined the status of women in the history of traditional Chinese culture (Yi, 2006). Confucianism is the mainstream of Chinese traditional culture. It has a significant impact on China ( $\mathrm{Li}, 2012$ ). In Confucianism, the relationship between men and women is the starting point for the whole social order and construction of ethical relationships (Li, 2012). During the Warring States Period (475-221 BC), people began to use term “男尊女卑” (respectable men and lowly women). This formed the gender system of Chinese feudal society (Yan \& Zhang, 1999). People considered women to be of lower status and weak from birth onwards. This traditional concept has deeply penetrated people's ideology. The Book of Songs, Odes of Wei is the first anthology of poetry in ancient China (Xiong $\&$ Wang, 2000). Many of the poems are "about abandoned wives or the troubles of family life". For example, Gu Feng, Ri Yue, Bo Zhou, Bai Hua and so on. These poems depict abandoned women who have grief (Xiong \& Wang, 2000).

"Mang" (Odes of Wei), is a poem about a woman who has been abandoned. It is different from other "abandoned poetry", because the woman does not believe that her marriage's failure is all her fault alone (Zhou, 2010). Her husband shares blame. Because of this, "Mang" is the representative poem of abandoned women (Xiong $\&$ Wang, 2000). In the poem the heroine is in a painful mood, recalling the sweetness of her love life, and the pain of being abused and abandoned by her husband after marriage. This poem expresses abandoned woman's remorse of rejection, reflecting how ancient society oppressed and devastated women (Zhou, 2010). In "Mang" the heroine not only tells her story in a painful tone, but also tells of women's consciousness and rationality: 
"[...]

Ah, thou young lady,

Seek no licentious pleasure with a gentleman!

When a gentleman indulges in such pleasure,

Something may still be said for him,

When a lady does so,

Nothing can be said for her.

[...]" (Legge, 2016)

In these sentences, we can see that the heroine has a good grasp of social propriety. In ancient times, women that had this kind of consciousness were very rare. You cannot find this kind of consciousness in "poems of abandoned women" in The Book of Songs. The heroine laments being married to a bad husband. She has to face a kind of helpless life:

"Thus [on my part] our contract was fulfilled,

But you have behaved thus cruelly.

My brothers will not know [all this],

And will only laugh at me." (Legge, 2016)

In the final lines, she accepts her life. Zhu Xi, who was a scholar during the Han Dynasty, commented that the abandoned heroine is an immoral woman in Poetry Biography, because she was in free love to get married (Xiong \& Wang, 2000). This comment reflects how Chinese society judged abandoned women. 


\section{The period of Republic of China (1912-1949)}

Chinese society transferred from tradition to modernity during the period of the Republic of China. People's values and the political system all changed (Chen \& Ye, 1998). These changes affected the traditional social structure and the marriage system (Chen \& Ye, 1998). The author, 二维 (Er Wei), describes a father taking his daughter out of school in “申报 - 自由谈” (Declaration of free talk). The reason is the father believes that women are incompetent, and dependent on men to live. Er Wei appeals that "Sisters, for women in the future, we have to tear up the old social system!" (Wang, 1998). In 1911, the feudal autocracy began to disintegrate after the establishment of the Republic of China. The traditional social relations began to loosen, and the old system of marriage was also affected. The new law clearly stipulated monogamy, the equal economic status of men and women, and freedom to divorce. The traditional marriage system disintegrated faster, and gradually lost its political foundation and legal protection (Sun, 2008).

During the period of the Republic of China, the government implemented policies on family and marriage. For example, the "Marriage Law" of 1931 stipulated that "a man only can have one wife. Polygamy is illegal". It also stipulated that "both men and women can initiate divorce". This introduced freedom of divorce to China (Sun, 2008). After these changes, more poor peasants could find girls or divorced women to be their wives. Marriage cost less, and rich men could not monopolise marriage by having many wives (Sun, 2008).

However, these stipulations were based on the Chinese Communist Party (CCP) revolution. Anna Louise Strong, an American journalist, wrote in her book, 中国人征服中国 (The Chinese Conquer China) (Strong, 1984), that one poor peasant spent merely $¥ 20$ to buy a wife because her father knew this peasant had land. In the CCP, peasants could become rich if they had land. Strong asked this man, "How did the revolution make women worthless"? He replied that women could divorce if they do not like their husbands so men no longer want to spend a lot of money on marriage. The revolution also brought another change: The government could now arbitrarily ask women to have more or fewer children. This ignores women's freedom of choice. "The Law of Marriage" was modified many times during the revolution. It is obvious that in several revisions the government gave up the liberation of women in order to consolidate and stabilise benefits for peasants. Sun states, that for the cause of the Chinese Communist revolution, women were always considered a tool for breeding, parenting, and population control (Sun, 2008). 


\section{After 1949 \\ (The People's Republic of China- PRC)}

For a long time, the institution of Chinese marriage has evolved. In April 1950, "The Marriage Law of the People's Republic of China” was promulgated in Beijing (Wu \& Xia, 2009). The new marriage law provided monogamy and free marriage.

By the 1950s, free marriage was accepted by society, but people had grown up in a conservative environment. They did not think about romance (Schneider, 2014). Therefore, any private desires for romantic love, intimacy, or happiness were considered as shameful (Schneider, 2014). This generation was living in a society tightly controlled by the Communist Party. The government assigned and supervised people's employment through the "danwei (单位)", or “work unit” system (Schneider, 2014). The "work unit" also controlled people's life, including travel, marriage, divorce, pregnancy, and birth (Schneider, 2014). Under the era of Mao, marriage could also be forced upon individuals. Firstly, some cadres of the Communist Party of China established a right to force people to marry them. They also disguised these forced marriages as consensual ones (Sun, 2008). Secondly, bigamy generally began to increase. For example, some cadres of CPC still had the feudal concept of polygamy ingrained. They got married to other women, but stayed in their first marriage (Schneider, 2014). Thirdly, the Communist Party prevented divorced women from remarrying (Sun, 2008).

While marriage in traditional society was mainly affected by the family, the marriage in the Mao Zedong Era was mainly controlled by the organisation. Marriage was dominated by money, market and property in the early years of Mao Zedong (Davis \& Harrell, 1993). In traditional society arranged marriage was popular, organised by the parents of the husband and wifeto-be (Ke, 2010). In the early years of the Mao Era, this tradition developed into the sale of marriage, requiring money and property as a condition of marriage. It was a serious violation of the principle of marriage based on love and the spirit of freedom of marriage. For example, $\mathrm{Mr}$ Chen spent five thousand Yuan to buy a wife from a vendor. And then, he priced his wife at 20 thousand Yuan to resell to others (Nie, 2003). In this example woman has no personal rights, she is a commodity to be traded among men. 


\section{In 21 st century}

In the 21st century, marriage privacy and personal freedom gained more respect. In 2003, the government implemented the "Marriage Registration Ordinance". This freed people from getting a certificate from their work unit or community to get married or divorced. While some freedom was gained, there are some other problems that women still have to face.

Traditionally, the social environment was one in which women were born to do needlework, to help the husband and to raise children. Women were not allowed to go to school, or to attend public events. “Nü zhu nei, nan zhu wai (女主内, 男主外)” came from the “I Ching”. It means that women are located at home, men are outdoors. Marriage and family became the most important part of a woman's life, and people began to use the phrase "To do well is inferior to marrying well”. In modern society, women can go to school, and work. So, why do people still have the idea that "To do well is inferior to marrying well"?

In China, there is a very famous variety show which is called "If You Are The One". It is currently the most-viewed Chinese dating show (Yin \& Huo, 2010). In three rounds, 24 single women learn about the male guest. Each round, they chose whether the male guest enters the finale where he elects one of the single women as his "heartbeat girl". In this dating show, there are many female contestants with high education and a good job, and some even have their own company. However, their point of view is that the most important thing in life is to marry a good husband. Their mothers agree with this perspective, and believe that their daughters are intelligent girls because of this.

Followers of traditional patriarchal ideology believe that women and men are different, and that this male chauvinism is natural. This idea that has been around for thousands of years is unjust and outdated (Huang, 1997). Scholars cannot avoid the feedback loop between conventional attitudes and social reality. In the past, a woman's whole life was lived in private areas, and people barely ever saw women socialising. The ancients never thought of Chinese women going out to earn money, going to school, being present in all walks of life. The importance of women in society has changed because of social development, openness and progress (Lan, 2011). Chinese women's liberation will depend on each woman taking power for herself, really for herself, and not with a man. And only in that way will Chinese women gain equality (Li, 2012). 
3

Literature Review 


\section{Feminism in China}

Feminism has existed for more than 100 years in the Western culture (Wang, 2012). The women's liberation movement came into existence in China's modern history due to China's reform and opening to the outside. Although Chinese feminism was influenced by Western feminism, the Chinese women's movement is not the same as the Western women's liberation movement that is opposed to patriarchy in the law. The Chinese women's movement demands that the law protects women and men equally. The movement aims to achieve this goal peacefully. In mandarin, feminism (Zhu, 2014) represent two different meanings which correlate to two different women right movements before and after 1960. The first meaning 1) “女权主义” (Nü quan zhu yi) (Chen, 1995) mainly refers to the rights of women. Before the 1960s, the aim of the Western women's liberation movement was to strive for equal social rights through nonviolent resistance (Zhu, 2014). For example, property rights, the right to vote. The prominent feature of the second meaning 2) “女性主义” (Nü xing zhu yi) (Zhu, 2014) signifies the struggle of the women gender itself, to portray both men and women as humans of equal level. In 1970s, Kate Millett, a leader of the modern women's movement (Magill, 2014), published her book Sexual Politics that became a symbol of theory in the second wave of the Western feminist movement (Zhu, 2014). My research will investigate Chinese feminism by focusing on gender equality in Chinese marriage. I will use the second translation (“女性主义”) to define Chinese feminism in art and design. 


\section{Feminist Artwork}

In the second wave of the Western feminist movement, American art historian Linda Nochlin inquired "Why have there been no great women artists?" (1989). This was the prelude to feminist studies in the field of art history (Wang \& Liu, 2015). Over the next 30 years, some female artists emerged and grew up in the feminist movement. They used their experiences and perceptions to interpret the world's new perspectives. In the 1960s and 1970s, feminist art appeared in the West, then gradually spread around the world. Chinese feminist art as a new product became active in the 1990s ( $\mathrm{Ni}, 2006$ ). In 1994, Hong Xu published her work 'Walk Out of the Abyss, An Open Letter to Female Artists and Female Critics' in Jiangsu Pictorial (Cao, 2013). The letter opened the door to investigate Chinese feminist art. The emergence of "Feminist Art" has become a new and unique phenomenon in contemporary art of China (Zhou, 2005). Some artists publicly expressed their female identity, and in 1990, the exhibition of "The World of Female Painters" (Jia, 2003) marked the rise of female artists. In March 1998, the largest female art exhibition in China, "Century Woman", was held at the Chinese Art Museum (Jia, 2003). 


\section{Gender Inequality}

In comparison to Western women's art, Chinese women's art started late. The investigation of Chinese women's art is not only dependent on the development of feminist art in China, but also on the process of Western feminist art research (Cao, 2013). Early feminist artists believed that their art should be about women's concerns (Teng, 2007). The desire of female artists to express their concern has become more and more intense and profound. Female artists are different from male artists in early period in that they are concerned about social change and other major issues. They are intimately concerned about their own change, and everything that is closely related to their lives. They use these themes to express their inner feelings (Teng, 2007). Female artists used the universal symbols of female identity - such as the female genitals, body and body language - as subjects in their works (not only works of art, but also literature). Women watch their bodies through their own eyes, which is an important point for women's self-determination and self-actualization (Wang, 2006). The "Female Body" has become a medium, a form, a concept and a narrative of the importance of female subjects in early feminist artworks (Wang, 2006).

Twelve Flower Months is created by Lingyang Chen. This artwork is made up of photographs taken from the end of 1999 up to the December 2000. Lingyang Chen combined a vein of thought in Chinese traditional village Taoism with her own cultural interpretation (Jörg \& Zhou, 2014). She used a lot of different elements in Twelve Flower Months. She recorded her periods of bleeding, she followed the time sequence of different flowers for a year, she used reflections from her own mirror, and she drew shapes from Chinese classical garden windows.

"[...,] since this piece of art is based on tradition and also concerns women's very intimate experience, I set up a classical Chinese environment, exaggerating the beautiful, confined boudoir atmosphere. [.....] The placing of menstrual blood and the reproductive organs menstruation in a setting conforming to Chinese classical ideas of beauty is so unusual and unexpected the picture is all the more intense. I hope that the strong visual provocation caused by this artwork will set views thinking. "

------ by Lingyang Chen

In general, people would like to see a beautiful face and perfect body. In Twelve Flowers Months, Chen used, Chinese ancient mirrors to reflect classical elegant pictures, and female genitalia to express women abrupt, and her true life, and natural and elegant flowers to represent vaginas. In Twelve Flowers Months, the mirrors in the picture are an attempt to understand the self, a simile to help understand her true situation. 
In addition to use the way of symbolism to express feminism artwork, many female artists bare their bodies to convey social, tragic protest. Their expressions are not just about self-experience, but also concerned with women's pain and exposing the scars of pain (Wang \& Liu, 2015). 


\section{Marriage and Family}

For a long time, women were not respected in society, and so they yearned for freedom and political equality (Cao, 2013). From ancient to modern times, the value of women's social existence has been inseparable from family (Wu \& Wang, 2011). In China, some words defined the role of women in society, such as 'Housewife', 'Nan Zhu Wai, Nv Zhu Nei' (男主外, 女主内). This translate as "women take care of family matters, men work outside". Despite all responsibilities of a housewife, she still has a lower position in the family than her husband.

Due to feminism's influence on the Chinese art world, Chinese female artists now often explore the relationship between women and family in their artworks (Cao, 2013). The artist Liu Manwen uses her own experience as a creative source in her works. She describes an ordinary family life that is not harmonious and warm, but depicts the conflict between family members, and the situation of women. Through these depictions she aims to reflect the position of women in the family and social roles (Cheng, 2011). A series of works titled 'Ordinary Life' is one of the important examples. In this series of artworks, the artist re-interprets the value of women in the family. Chinese family is not only about an individual couple, it is a complex shared space.

All of Liu's works use dark color to evoke the spiritual word (Zhou, 2005). In one picture, a housewife with a very cold face is busy taking care of her husband and son. Even in her own environment she shows indifference. For example, "No title" expresses the space between men and women. The couple are emotionally alienated from each other by numbness and confusion. The series Ordinary Life has nearly 20 works, and these works are based on the concept of the family (Cao, 2013). Liu bases her work on familiar family types in her life, and from there launches further analysis of the contemporary Chinese family, especially the two parent and one child family brought about by China's historic one child policy (Cao, 2013).

"Ordinary Life 9" actually records the life of the wife, husband and children. The picture depicts the space as closed and static. People only can see a thick white mask covering the wife's face. She conveys numbness and indifference through her eyes. The wife's hands clasp to her chest as if it were an unconscious self-defense, behind her is a boy and a husband who takes photos (Cao, 2013). Through the contents of the picture, we can see the artist feels bored and helpless about family life. Liu believes that modern women should have their own independent human rights and value of existence, and should be widely respected (Cao, 2013). 
"Fashionable technology refers to the intersection of design, fashion, science and technology [...] Fashionable wearables are 'designed' garments accessories or jewelry that combines aesthetics and style with functional technology. As designers of fashionable wearables, we view end users as fashionable beings who are attentive to style and powerful potential of wearable technologies. Our design philosophy is based on the notion that garments are the immediate interface to the environment and thus are a constant transmitter and receiver of emotions, experiences, and meaning." (Seymour, 2008) 


\section{Wearable Technology \& Wearable Art}

The role of clothes is not only to protect people's bodies, but also has been given a wealth of cultural and functional elements. In the 21st century, people are looking for new ways to construct their clothes by using new materials, or including technology. Traditional garments are not enough to allow designers to express their inspiration. Wearable technology accessories such as the iWatch or Fitbit help people to enjoy their life. Wearable Technology can also combine fashion and technology to create interactive design.

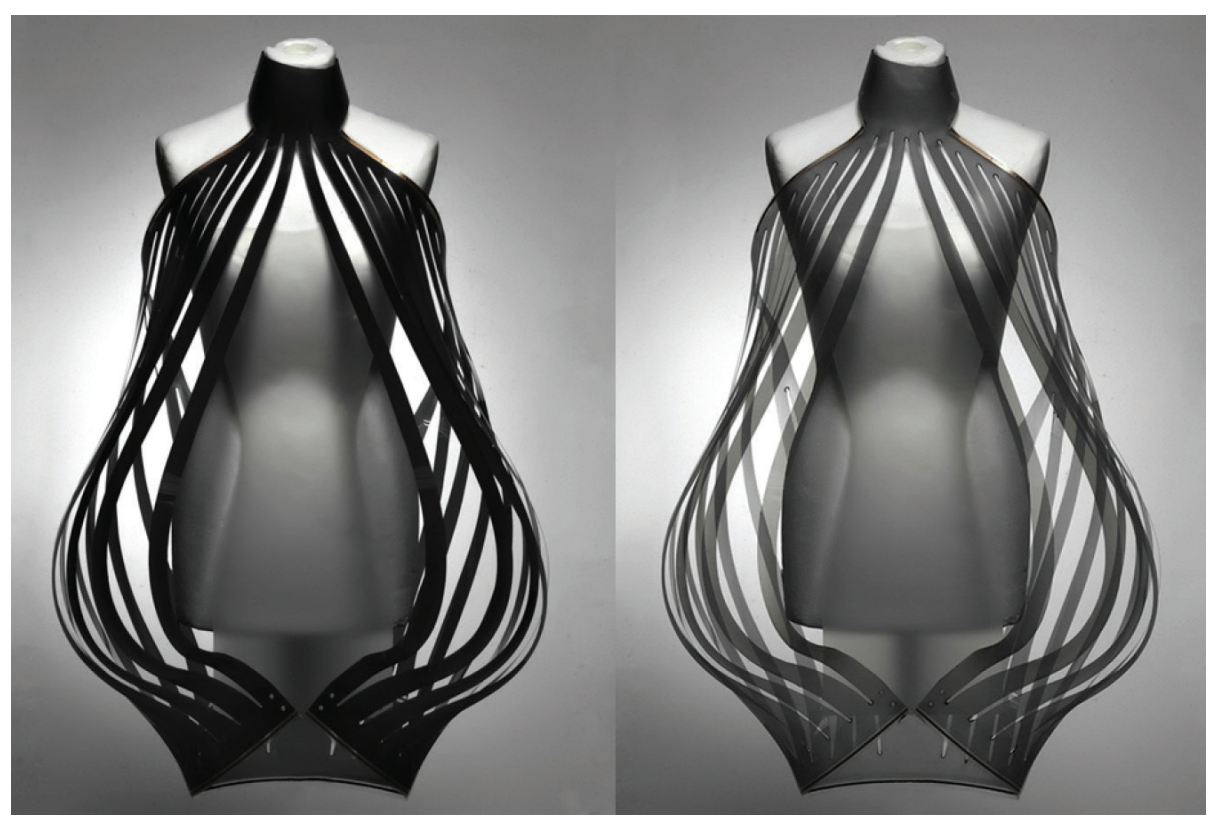

Figure 3.1. Intimacy Black 
INTIMACY (Studio Roosegaarde, 20102011) is a fashion technology design by Daan Roosegaarde. The high-tech garments ("INTIMACY WHITE" and "INTIMACY BLACK") explore the body

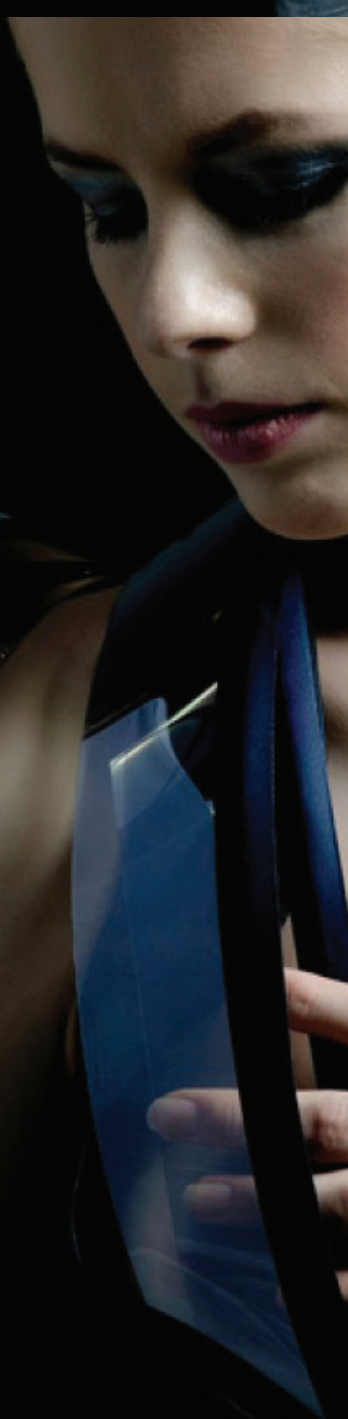
and technology. When the wearer's heart rate increases, the garments change from opaque to transparent. INTIMACY 2.0 is the new series by Studio Roosegaarde. This wearable dress combines leather and smart e-foils that respond to the wearer's heartbeat.

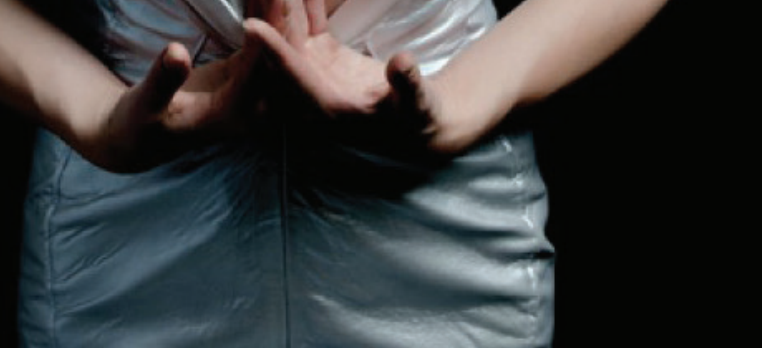


Wearable technology can make clothing responsive to the wearer's condition and actions. This provides more interactivity with wearers through different styles and different mediums. These interactive garments immediately express wearers' or designers' experiences, context, or visual preferences (Kwon, 2013).

Wearable technology can also have artistic uses. Today art can be many things and cannot be pinned down by medium, format or even context (Ryan, 2009). Art has often struggled for recognition when it worn on the body (Ryan, 2009). There have been a lot of wearable pieces evidenced in history around the world. However, people have not appreciated them as a cohesive practice (Ryan, 2009). Ryan (2009) argues that "it is with the rise of wearable technology-mobile media-that artists working with wearables have begun to achieve critical mass". Wearable garments reflect technological culture or culture's fascination with technology (Ryan, 2008).

Feminist art in China is recent and heavily influenced by Western feminism. A lot of Chinese art imitates Western feminism, and uses traditional media such as painting and sculpture. Wearable art is a modern medium and it is interactive with its audience. This medium could provide new ways for Chinese feminists to express themselves. 


\section{Precedent review}

For my precedent review, I sought out feminist artworks that express themselves in ways I thought were interesting for my own work. These works combine interactive design with fields like architecture, music, and fashion.

\section{Euphoric Femme}

Euphoric Femme (Teresa, 2011) is a series of audio visual artworks. Women collaborators created Euphoric Femme as an interactive media art installation. They used personal autoerotic image and sound recordings to positively explore feminism and sexuality. There are two projects. In the first project, Autoerotic Meditations, Teresa invites a variety of women online to create their personal autoerotic video and sound recordings. The artist edit themselves into an autoerotic meditation composition. In the April 2011 exhibition, Her Pleasure, Her Desire; Remix, which is the second project, audiences use a small interface device to trigger autoerotic meditations and sounds. The video material is remixed into different kaleidoscopic-like patterns that are projected onto the ceiling. A woman's sexual immersive experience in media art expresses sexual pleasure and wholeness of being.
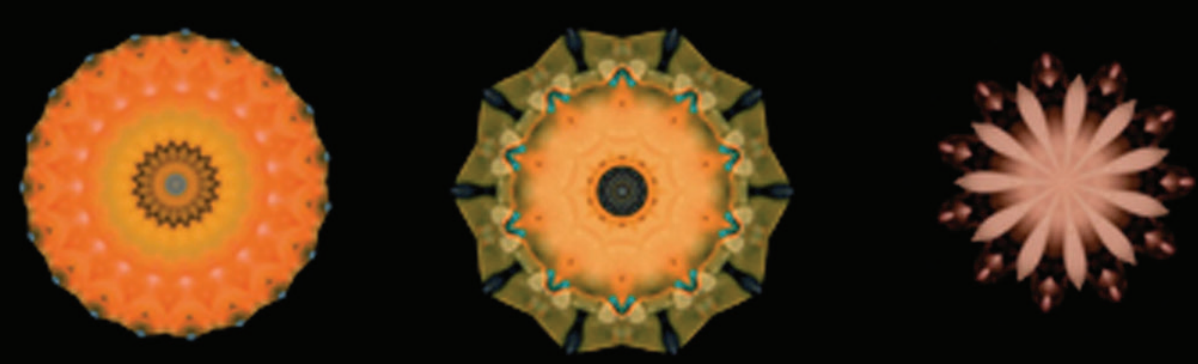

Figure 3.4. Euphoric Femme 
Teresa create this artwork through the following questions:

"1. What new art forms can be developed to express the elated mysteries of erotic pleasure and wholeness of being?

2. In what ways can women's sexual pleasure be illuminated while challenging sexual objectification?

3. How can sexual agency be facilitated through creative collaboration within a social media context?

4. How does interaction with women's autoerotic materials affect audience members?"

According to these questions, Euphoric Femme is different from other feminist art because it does not use nudity or genitals to express women's issues. It is a mysterious and delightful artwork. As Teresa (2011) explains "the title Euphoric Femme represents the core concepts and sensibilities in the artworks". 


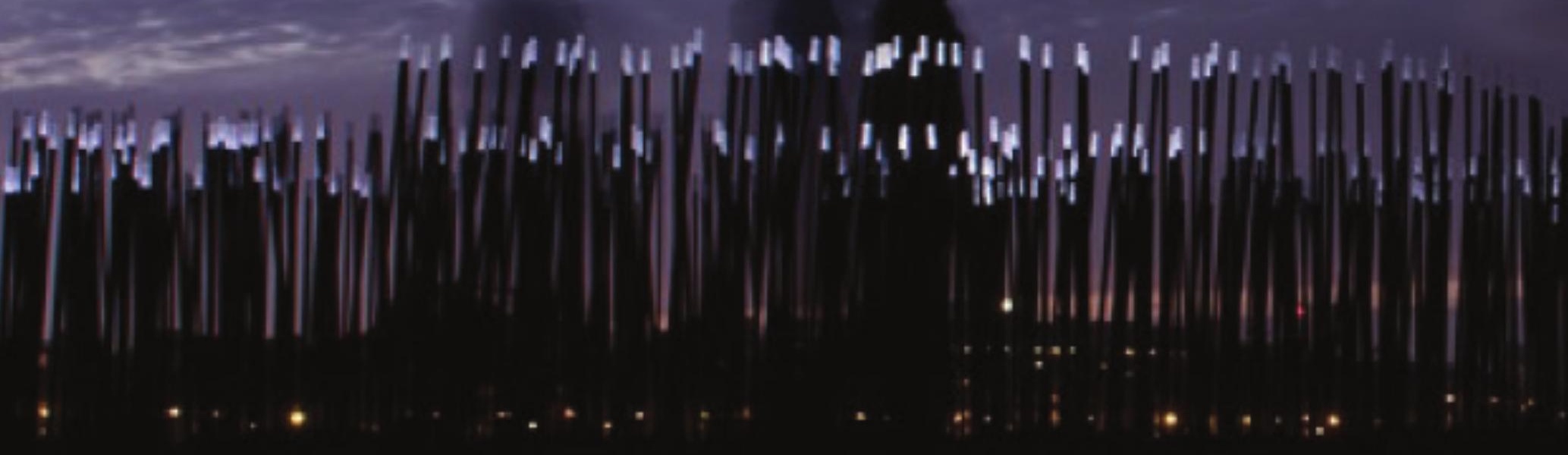

\section{DUNE}

DUNE (Studio Roosegaarde, 2006-2012) is a public landscape, interactive design by Daan Roosegaarde. This artwork is based on human behaviour, and combined with nature and technology. DUNE uses the sounds and motions of passing pedestrians to brighten fiber lights. DUNE exhibits in several public areas, for example the public pedestrian tunnel, and the Mass River in Rotterdam. These exhibits' goal enhance social interaction with visitors. The designer wishes people to enjoy their walk of light placed in the dark.

DUNE's goal is to explore the relationship between urban space and the future of nature by using lights that interact with visitors behaviour in the dark area. Daan uses new media to display that visitors are actively interacting with their environment. This is an easy way to give people a positive feeling. 


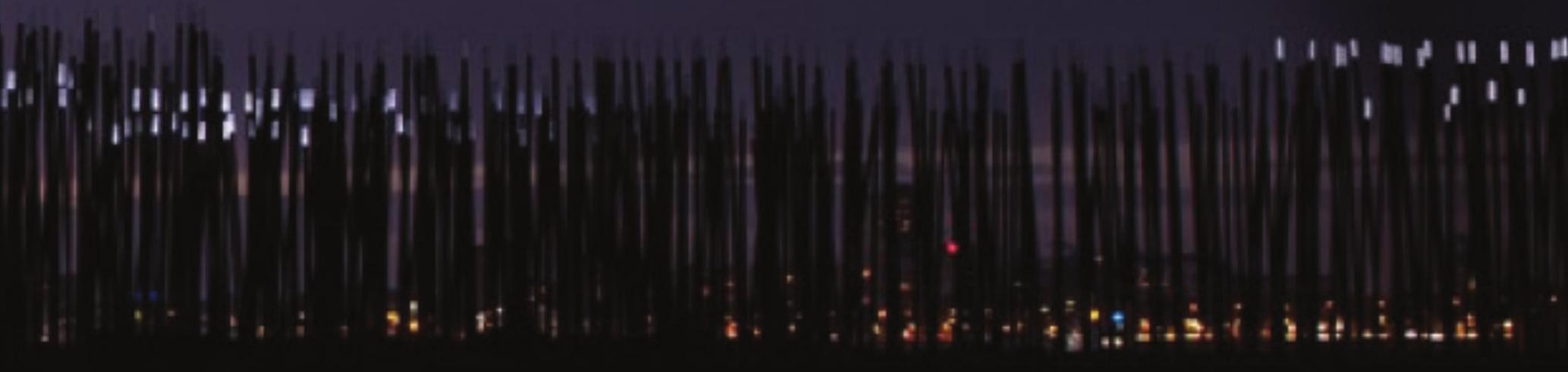

Figure 3.5. DUNE 4.2 


\section{Synaesthesia Playground}

Synaesthesia Playground (Ho, 2016) was an interactive classical concert experience performed at UCLA's Schoenberg Hall in 2017. The artist Jocelyn Ho brought together a world-class team to create this music-art-tech project. This project combines the audience's mobile phones and wearable technology to gamify classical music. This means that they audience participates in creating the music by playing their mobile phones like a game. The audience's mobile phones become musical instruments that can interact with the pianist on stage. The pianist is dressed in attire made from optical fibres that change color with the pianist's heartbeat, breathing, perspiration, and movements.

The visuals of Synaesthesia Playground are spectacular. Through multimedia design, these artists create a classical music experience that is immersive, interesting, and participatory.

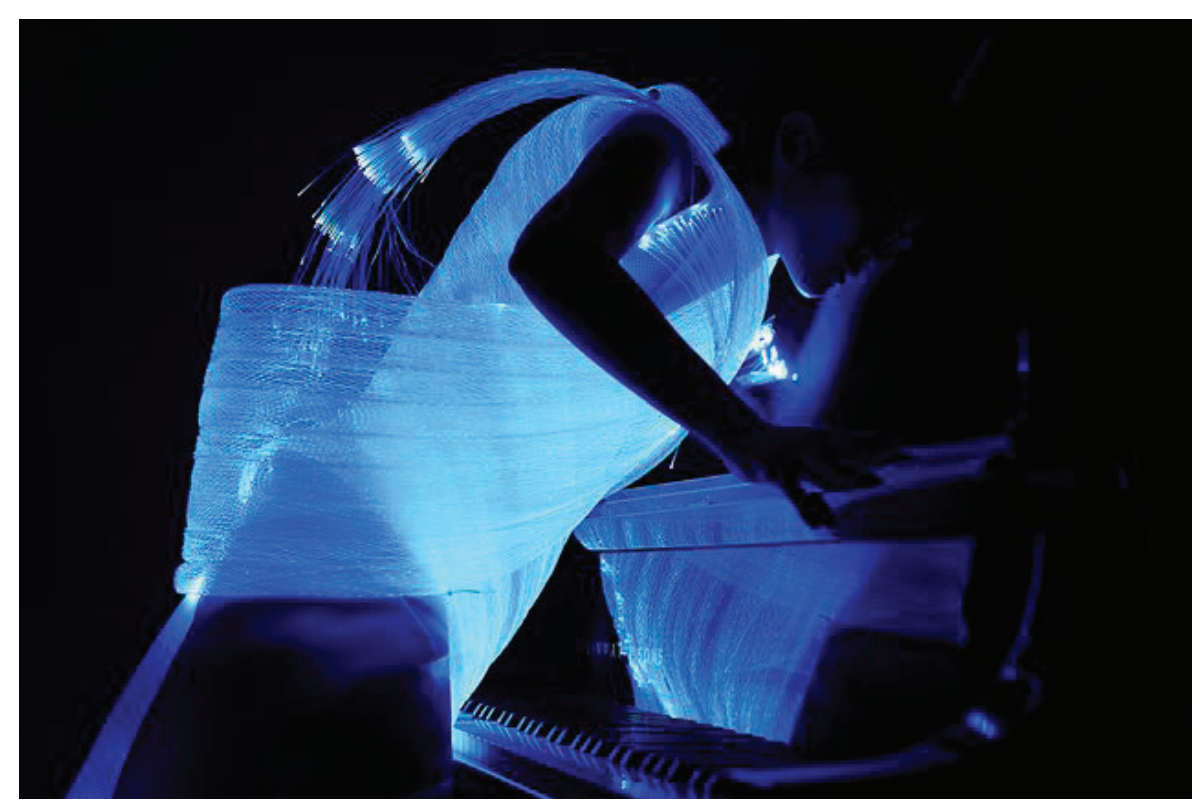

Figure 3.6. Synaesthesia Playground 


\section{Wo.Defy}

Wo.Defy (Ip, Chung, Lee \& Schiphorst, 2014) is an interactive wearable garment that integrates Chinese feminism and a somaesthetics framework for design, through integrating self-agency and self-reflection to express the 'Self-Combing Sisters'. The 'Self-Combing Sisters' was a group of Chinese women in the early 2oth century who challenged women's status in traditional marriage. These single girls changed their hair to a distinctive bounded bun or plait socially reserved for married women. Through this, they advocated freedom from the restraint of marriage. This design incorporates natural material, contemporary wearable design practice and integrates elements of feminist $\mathrm{HCl}$ (Human-Computer Interaction). The wearer's movements and breathing interact with this garment. Wo.Defy utilises force sensor to collect the rhythmic pattern of breathing and a tri-axis accelerometer collects the wearer's motion. These data determine the wearer's body status which is then expressed visually through lights and opening and closing of the interactive flower piece.

The concept of using movement, touch and breath to visually represent numerical physiological data is very interesting. Wo.Defy emphasises inner body expression through these functions. This can depict the feelings of the wearer visually. An example, breathing rhythms control LED lights and the floral elements' more frequent contraction. However this interaction is only initiated by the wearer, so there is a lack of interaction between the wearer and the audience.

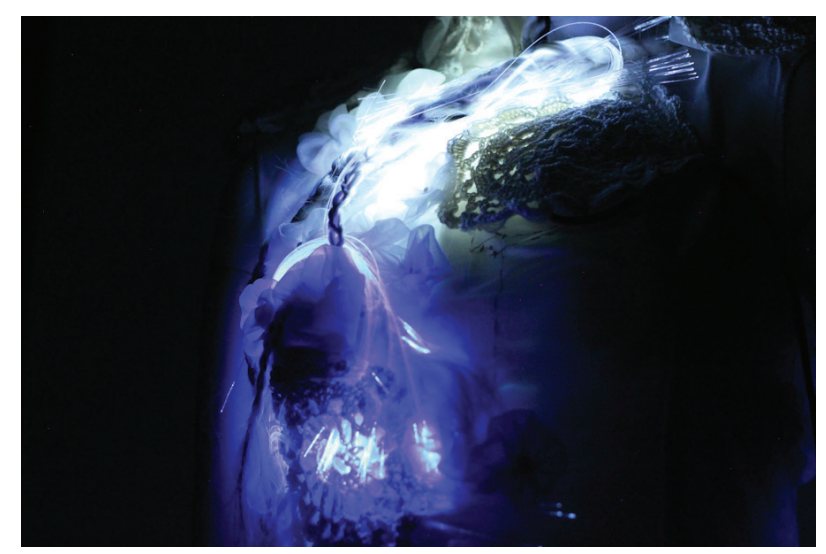

Figure 3.7. Wo.Defy

These precedents are all examples of works in which technology supports and enhances the artistic expression. Feminists can use wearable technology to express the long recurring issues of feminism in China. This can modernise feminist art, and artists will be able to convey issues in a new way. 


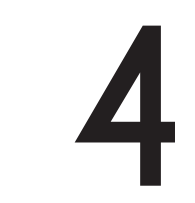

Method 


\section{Areas where Chinese artists have not explored}

There are some areas of feminism that Chinese artists have not explored, based on my findings. In China, expressions of gender are becoming more popular in feminist artworks. There are some artists that use children, husband or element of family life in their artworks. Many artists use domestic themes in their work and this also risks monotony. Yang Xue (2010) argues that female artists should not only express personal life experiences, but also need to think and create from the social and human perspective. There are a lot of the works that take a critical stance on feminist issues in Chinese feminist art. There is a lot of important critical work that uses controversial tactics such as showing female organs, exposed bodies, or which combine bloody scenes with the female body. I chose to avoid these expressions, and to study works which are contemporary way, but still critical. I prefer to explore works such as Euphoric Femme. There are few artists who use new ways to express feminist ideas, such as the wearable technology garments Wo.Defy. Wearers can get physical feelings or responses back from a garment.

Based on my previous research, almost all Chinese feminist work uses traditional media such as painting, sculpture, and performance art. In the 21st century, wearable technology is combined with different fields of culture such as music or architecture. However, there is little feminist art that combines Chinese feminism with wearable technology. This is a gap I want to investigate, and it motivates my garment design. My research looks for 'How and what wearable technologies could most effectively critique gender inequality in marriage from a specifically Chinese perspective?'

\section{Aims and Objectives}

\begin{tabular}{|c|c|c|}
\hline Aims & Objectives & Method \\
\hline \multirow{2}{*}{$\begin{array}{l}\text { Use wearable technology } \\
\text { to address the issue of } \\
\text { feminism within Chinese } \\
\text { culture }\end{array}$} & $\begin{array}{l}\text { To investigate feminist issues in } \\
\text { relation to married women in China }\end{array}$ & Background \\
\hline & $\begin{array}{l}\text { To review how the issues of } \\
\text { feminism in China can be expressed } \\
\text { through art and technology. }\end{array}$ & Literatre Review \\
\hline \multirow{2}{*}{$\begin{array}{l}\text { To design a garment that } \\
\text { questions gender equality in } \\
\text { marriage from a specifically } \\
\text { Chinese perspective }\end{array}$} & $\begin{array}{l}\text { To explore material and interaction } \\
\text { technology }\end{array}$ & $\begin{array}{l}\text { Material and electricity } \\
\text { experience }\end{array}$ \\
\hline & $\begin{array}{l}\text { How to construct the narrative and } \\
\text { design a garment that speaks to } \\
\text { this narrative }\end{array}$ & $\begin{array}{l}\text { Visual precedents and } \\
\text { Questionnaire }\end{array}$ \\
\hline
\end{tabular}


5

Exploration 


\section{Questionnaire \& Result}

In order to investigate the unequal treatment of Chinese women in marriage, I conducted an online anonymous questionnaire in Mandarin using WeChat (WeChat 6.5.8, Tencent, 2011). This is a Chinese social media app that enables people to chat with their friends and check their friends' updates. It asked about spouse selection, the role of women in Chinese marriages, and what people think about divorced women. My questionnaire had 64 participants (32 males, 32 females), and was limited to urban populations. The age range of my participants in this questionnaire is from 20 to 60 years old. However my participants skew heavily towards 20 to 30 years old. Older participants are outliers. 


\section{Views about spouse selection}

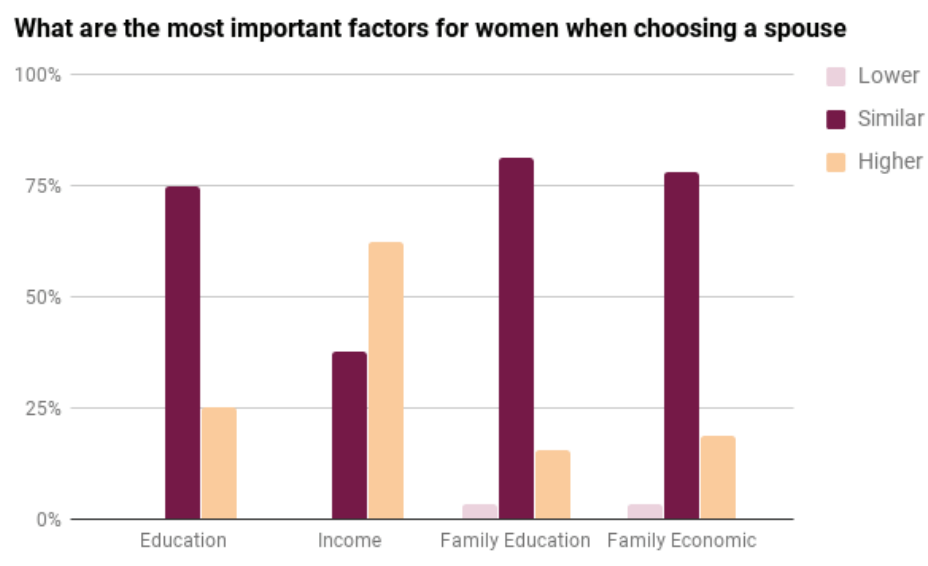

Figure 5.1

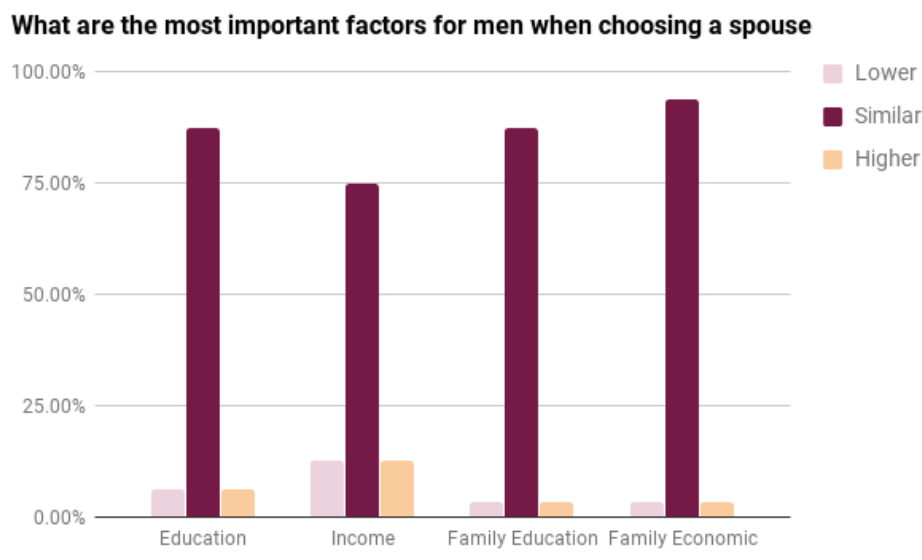

Figure 5.2

From the result of two charts above, people tend to choose someone who has a similar background with them as their spouse. Some of the female participants remain to think that male should be at a higher level in all aspects especially when referring to the aspect of income. None female participants are willing to choose a male whose level of education and income is lower than themselves. The situation of how men choose their spouse is slightly different. Based on the result of figure 5.2, some of the male participants would like their spouse whose level of education and income is lower than themselves. According to the information, although people's standard of spouse selection has tended to gender equality, the traditional Chinese marriage culture still affect Chinese people. 


\section{The role of women in Chinese marriage}

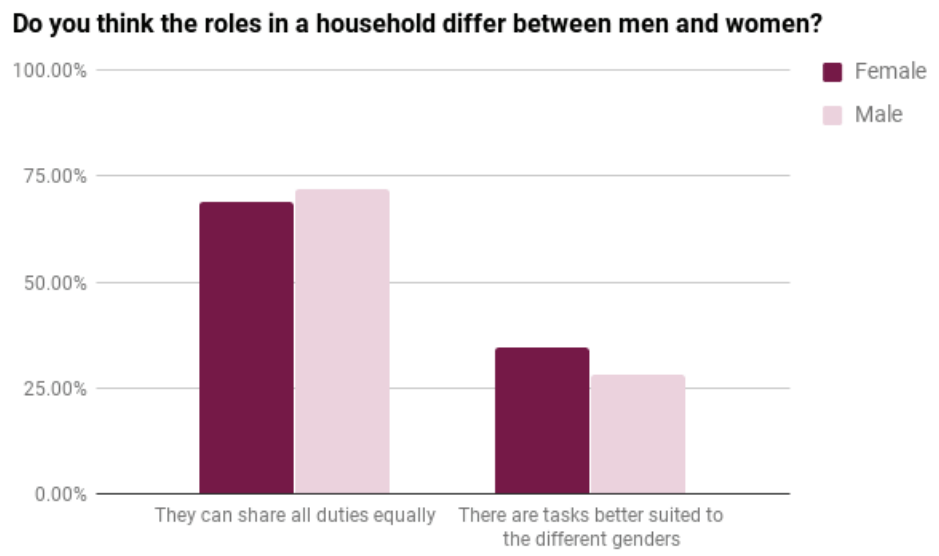

Figure 5.3

According to the result of figure 5.3 above, most people think that couples can share all duties equality in a family. Comparing female and male participants, male participants are more likely to think that a couple can share all duties equality in the family. More female participants said that couples should have gender-specific tasks. 


\section{Divorce women}

1. I think it's shameful

2. I feel pity for her

3. I don't feel they should marry again

4. Women are more experienced and

therefore more valuable after divorce

5. I don't see any difference between a

single, married or divorced women

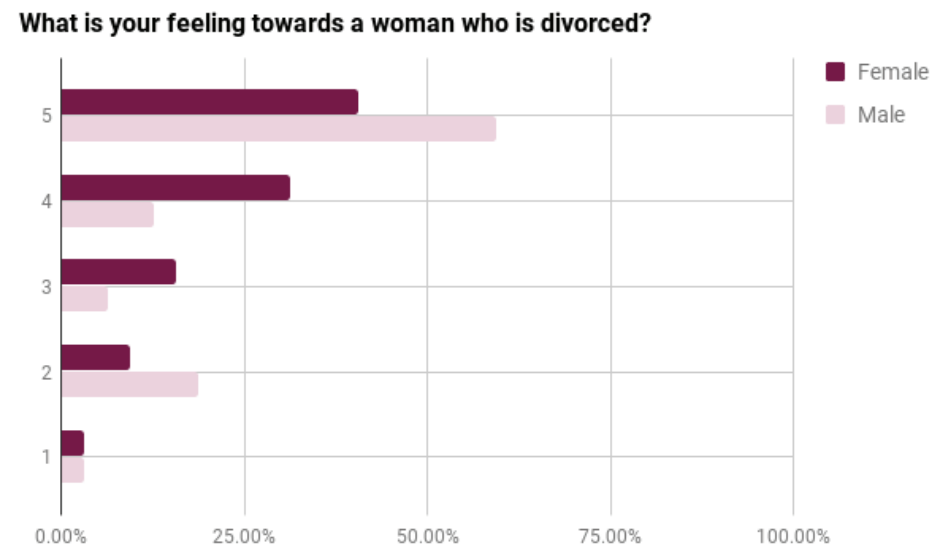

Figure 5.4

As can be seen from the chart, most male participants do not think that divorced women are different from a single or married women. Although some male participants feel pity for divorced women, some people also believe that women are more valuable after divorce. Most female participants believe that everyone is same. Even though women have divorced, they are more experienced and more valuable. However, more female than male participants believe that a divorced woman's is unlikely to remarry.

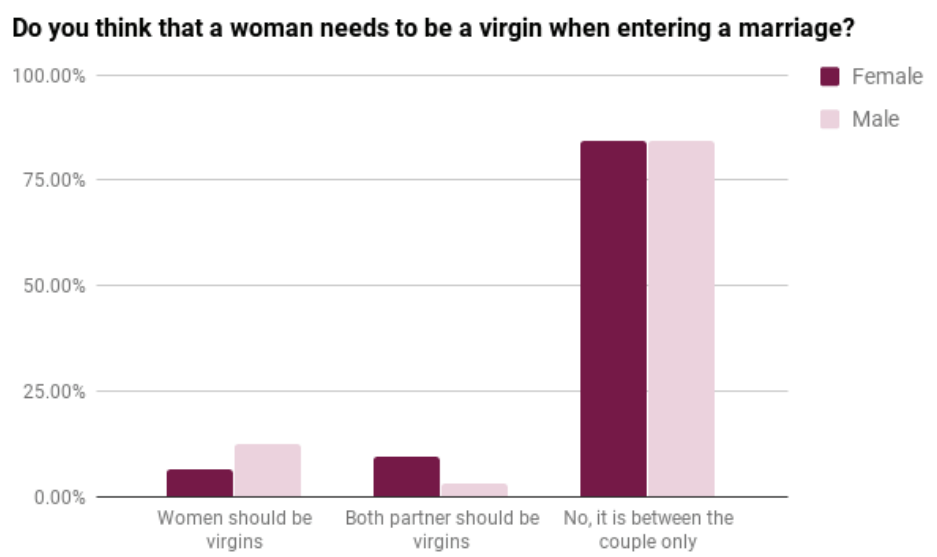

Figure 5.5 
As shown in the figure 5.5, people think that women do not need to be a virgin when entering a marriage, it is between the couple only. Female respondents account for the same percentage as male respondents. Comparing the first option and the second option, more male respondents tend to believe women should be virgins.

The results of this questionnaire show that there has been a positive development in gender equality in marriage. However, some participants still have more traditional views. As we can see in news reports there is still gender inequality in marriage. In recent years, Chinese media has created concept of the "leftover women". They use this term to refer to unmarried women above the age of 27 (Chen, 2016). Heather Chen of BBC News has written an article entitled the “Emotional Advert about China's 'Leftover Women' goes viral.” This advertisement went viral in China in 2016, beginning a debate about single women in the country. Chen describes different views about marriage, including those from single Chinese women and their parents. One interviewee said: "In Chinese culture, respecting your parents is the most important quality, and not getting married is the biggest sign of disrespect. (SK-II, 2016)". Another woman said: "People think that in Chinese society an unmarried woman is incomplete (SK-II, 2016)."

My questionnaire had a small sample size, limited to urban populations. This means its results are not broadly representative of what most people think. My questions also had limits. In fingure 5.3, although people would like couples to share all family duties equally, what they consider as "sharing" may not be a 50/50 split. Some people may believe that women taking 60\%-70\% of the housework is "sharing". According to the result of figure 5.5, most participants believe that women do not to be a virgin when entering a marriage. In recent months, a TV play has caused a lot of discussion about "whether women are virgins before marriage". At the same time, a college in Jiangxi, China, organized a public lecture called "Traditional culture into the campus". At this event a woman lecturer discussed female virtues. She said "if women wear revealing clothing, they will easily lose their virginity", and "a girl's best dowry is virginity". This news caused a lot of discussion in social media, and caused some women to worry that their future husbands will look down on them because they are not virgins.

From these examples, I can conclude that Chinese women do not yet have gender equality. Today, they are still fighting for equal rights. 


\section{Design Concept}

I will design a garment that:

- Is interactive

- Expresses the restriction of traditional Chinese marriage through physically constraining the model in a way that reflects some women's discomfort in marriage

- Makes the audience think about traditional Chinese marriage and women's freedom

A Chinese traditional wedding has it own special attire that is totally different from western attire. Red has special significance in Chinese culture. People believe that it can bring them good luck. Because of this, red plays a vital role in Chinese wedding festivities, and is the color of the bride's dress. Red is to the Chinese wedding dress as white is to the Western one - pure and sacred. My design concept will use red to represent traditional Chinese weddings. It will use technology or other elements to represent modern Chinese culture. Using basic ideas, I drafted the following concepts: 


\section{Concept A}
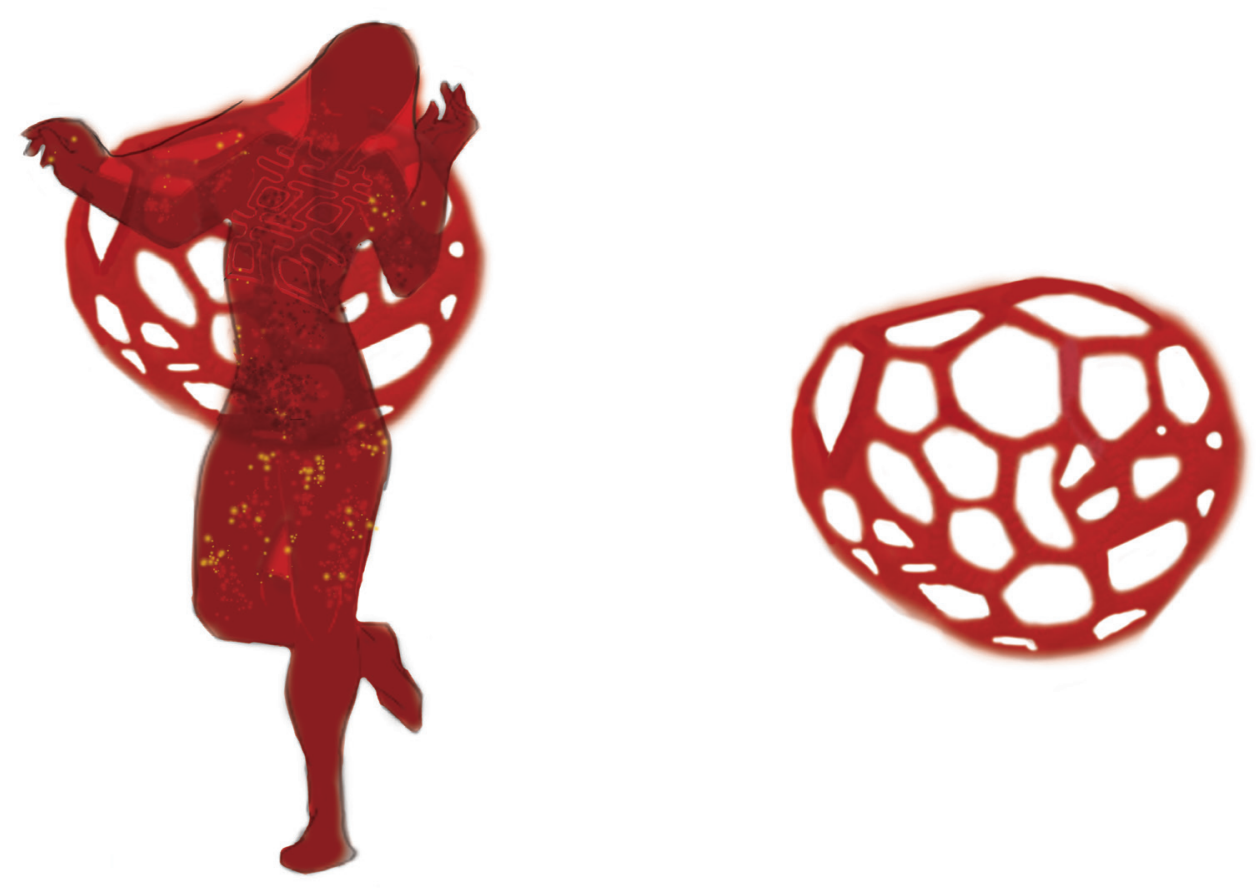

Figure 5.6

This concept combines two parts which are bodysuit and cage. The bodysuit represents the unfairness in women's life. The model struggles to free herself through stretching the fabric. The cage represents traditional Chinese culture as a prison that contains them. There will be lights on the top of the bodysuit. The lights will fade when the model stretches the fabric. I intend the number of lights to express women's painful feelings. 


\section{Concept B}

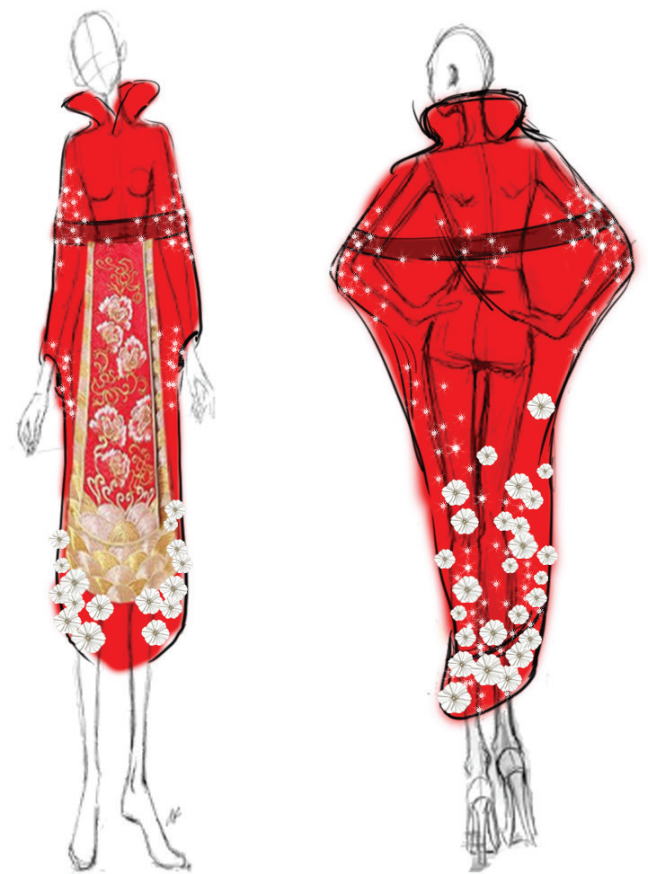

Figure 5.7

Flowers on the garment open and close. For this function, I have two ideas:

1. They react to the noise level of audience, opening when it is quiet and closing when it is loud

2. They react to the distance between wearer and audience, closing when the audience comes near
A traditional Chinese wedding dress, "Qun Kwa (裙 褂) generally shape looks like a trapezoid (narrow above and wide below). Tradition dictates that Chinese women should walk slowly and dignified, a very casual walk is not lady-like even if the dress is very easy to walk in. In this design concept, the skirt is wide above and narrow below. If the model wants to walk fast, the skirt will block her. The belt is decorated on the waist in Chinese tradition. An elastic band makes a belt around the model's chest, representing unfairness. This concept combines more elements from Chinese traditional wedding dresses, such as the pattern and embroidery. LEDs will be placed on the arm and under the skirts around the knees. When model moves, lights will turn on by the stretch of the fabric.

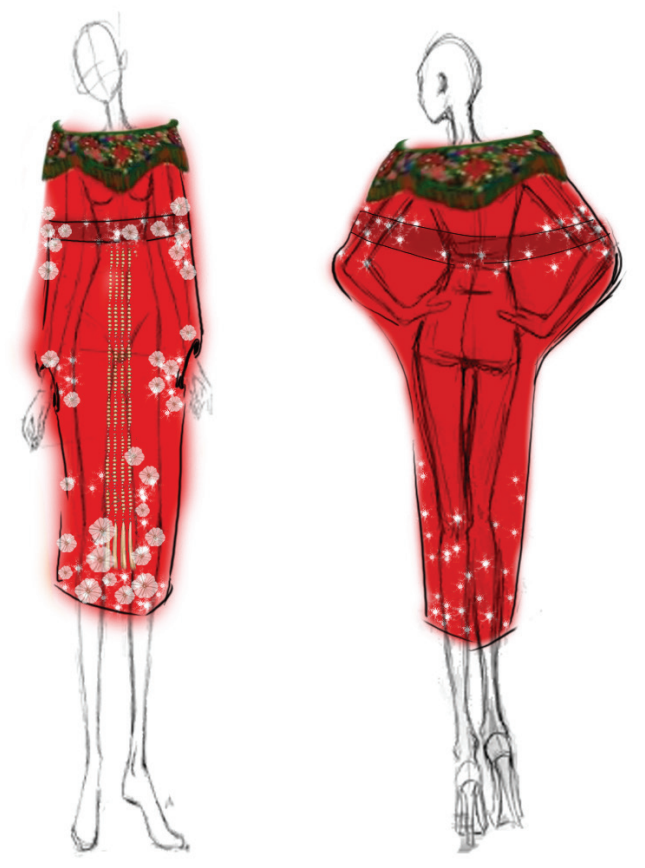

Figure 5.8 


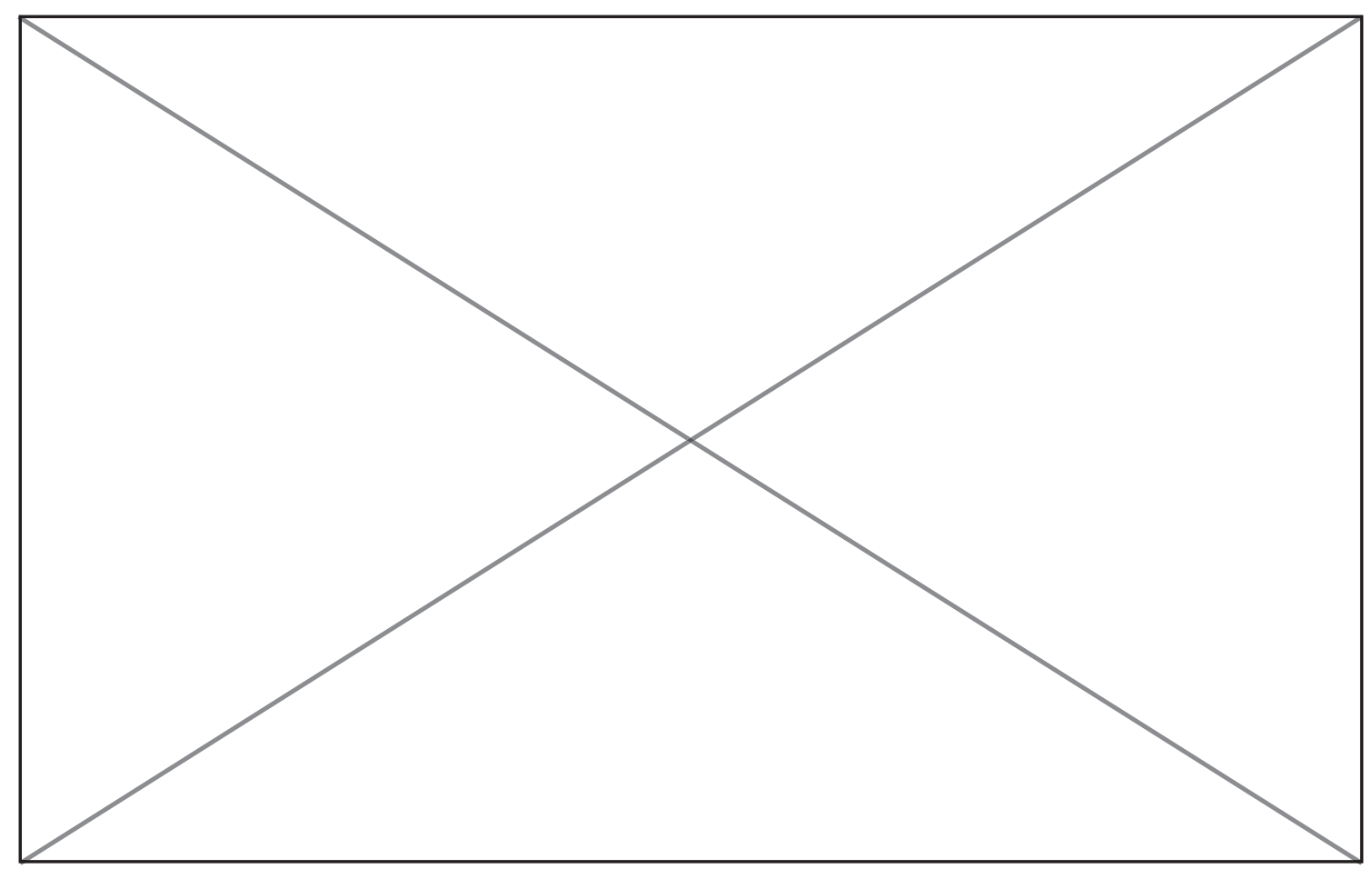

Figure 5.9 Evolution of Chinese Clothing and Cheongsam

This photo shows that women clothing timeline in Chinese ancient time 


\section{Concept C}
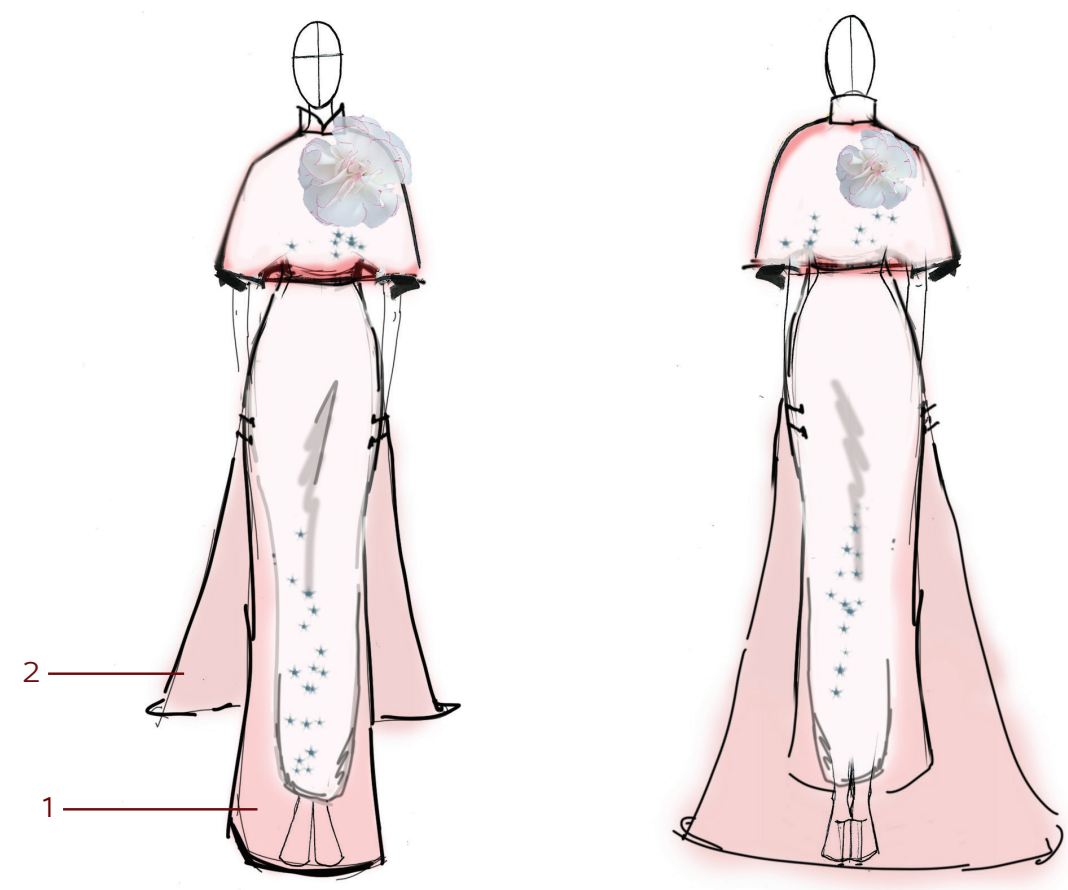

Figure 5.12

This concept combines Western and Chinese culture. I made the inside dress white, and the outside dress red. The top part of the garment is a white fabric and can be stretched. A red fabric that cannot stretch surrounds the white fabric. This design means that when the model wants to stretch their arms wider, the red outer layer resists the model's movement. For the skirt, the inside is white and can also stretch. On the outside, red fabric makes a cheongsam (旗袍) (a traditional Chinese wedding garment). The layer marked 1 in my diagram is cheongsam shaped. Layer 2 is more like a Western garment or a traditional Chinese male wedding garment. 


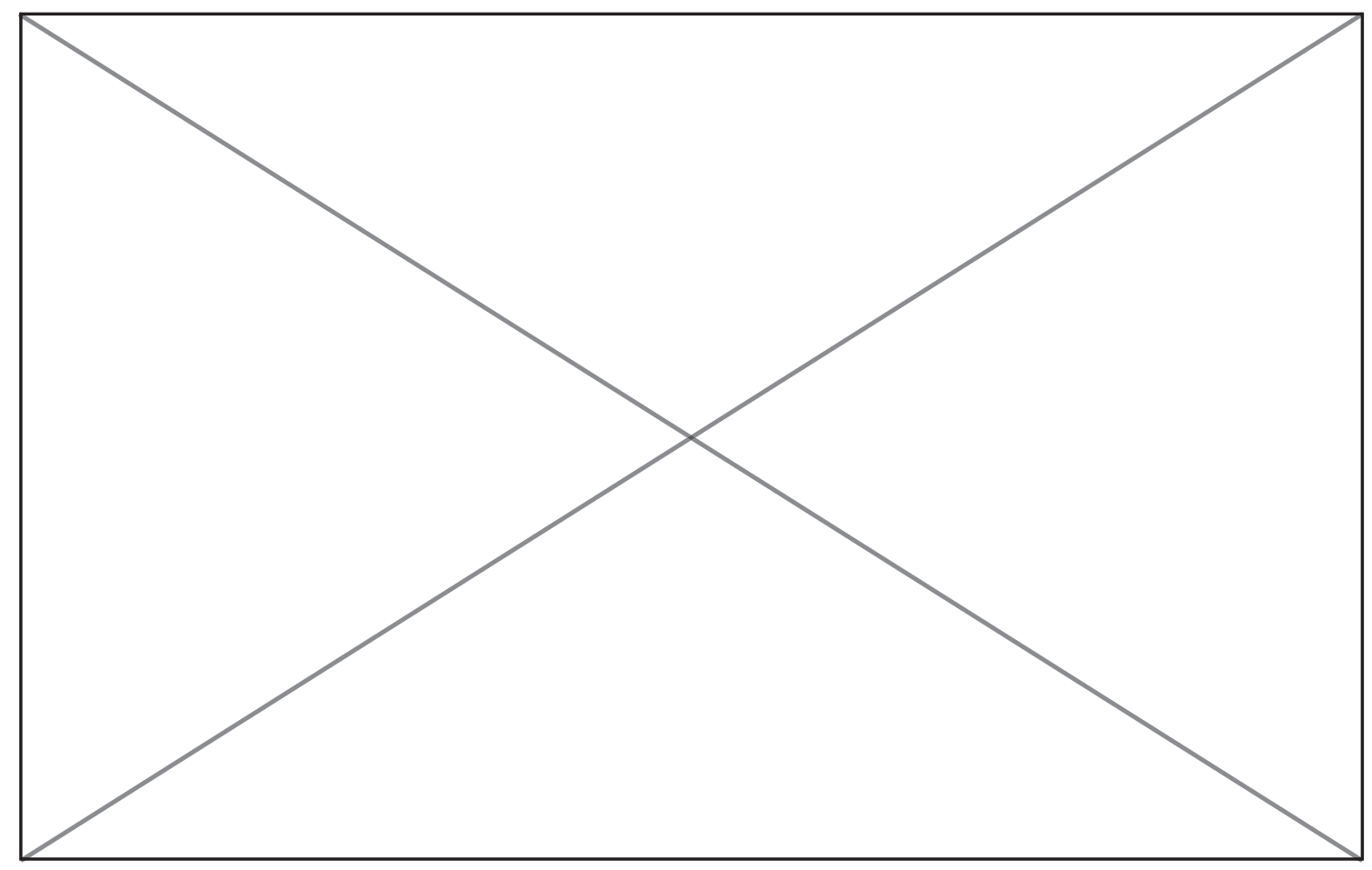

Figure 5.11 Evolution of Chinese Clothing and Cheongsam

This photo shows that fashion timelines of Chinese cheongsam 


\section{Design Development}

After reviewing my concepts above, and researching Chinese wedding attire further, I further developed my garment design.

\section{Yún jiān 云肩 (Shoulder Cape)}

The "Yún jiān (云肩)" or "shoulder cape" is an accessory that women only wear as brides. The pattern of the shoulder cape consists of artistic symbols. Different shoulder capes have different theme, but all of them are inseparable from the good wishes of love and marriage. In addition, shoulder capes also represent protecting women. The traditional shapes of a shoulder cape is symmetrical as a quartet or a circle. My design concept uses asymmetrical shapes on the left and right sides, one side is sharp shape which is stretching away as a armour. It is representing men's masculinity. And the other has more gentle contour representing women's femininity. I designed six different shoulder capes using the idea that women can be as strong as men. I designed these to arrive at my final design.
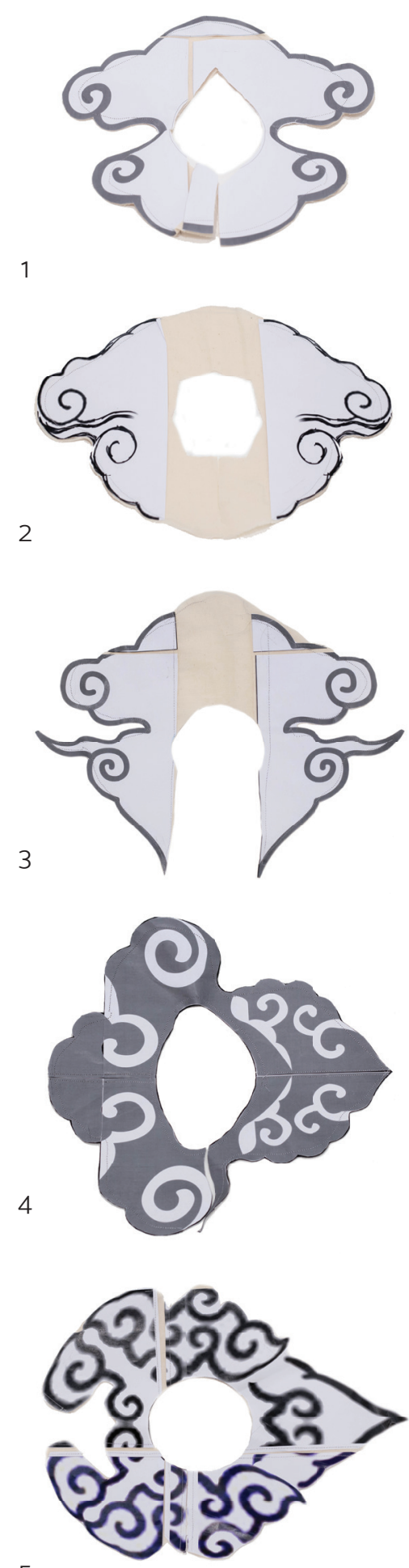

5

Figure 5.12

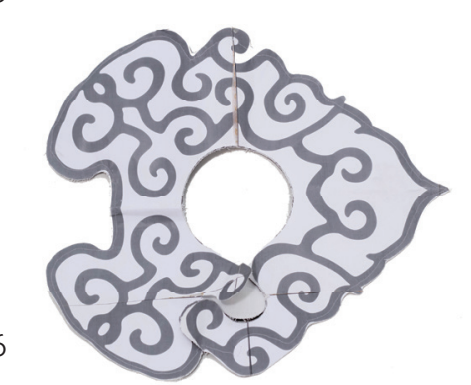




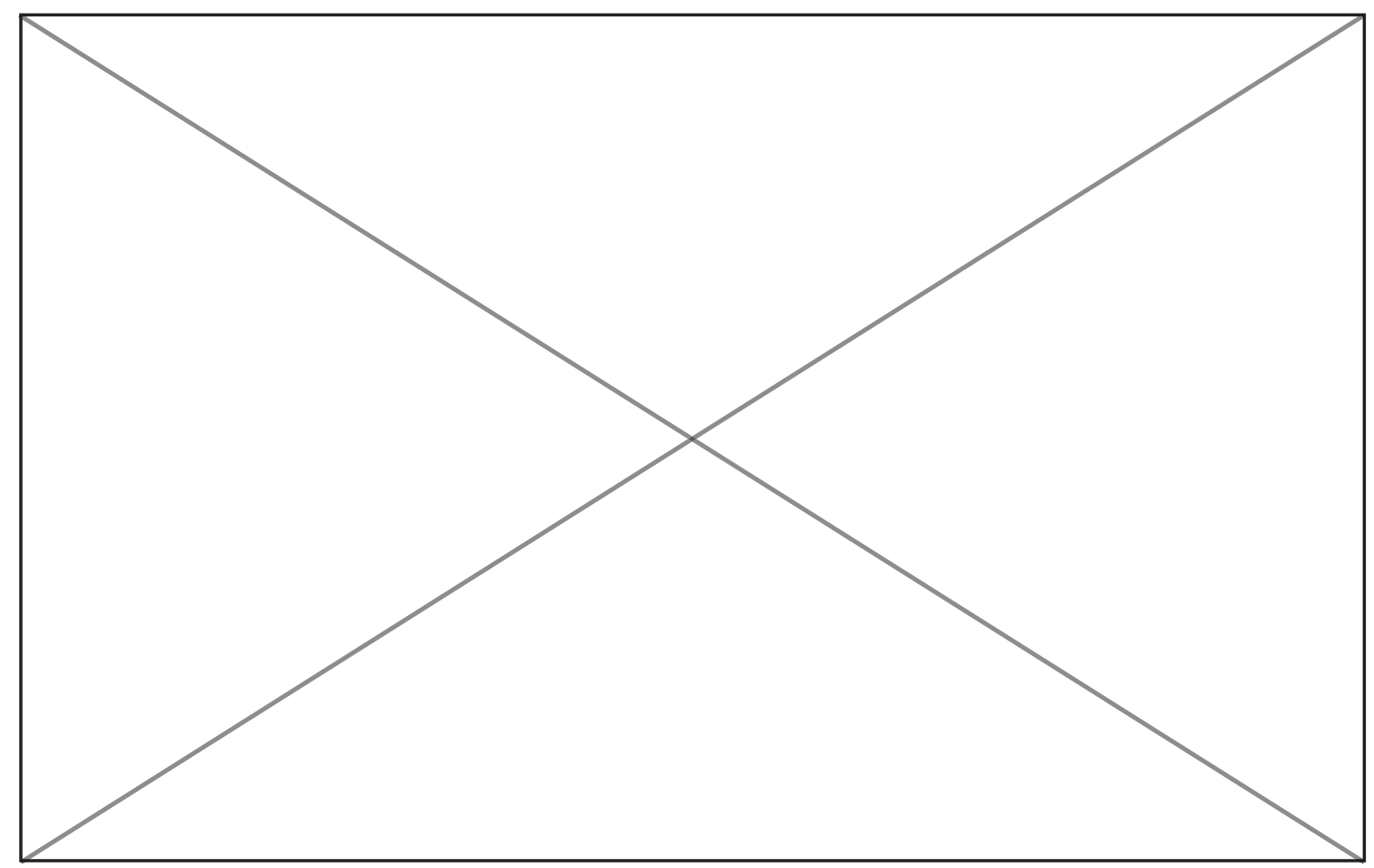

Figure 5.13 Yún jiān 云肩

These photos show that the traditional shapes of a shoulder cape is symmetrical 


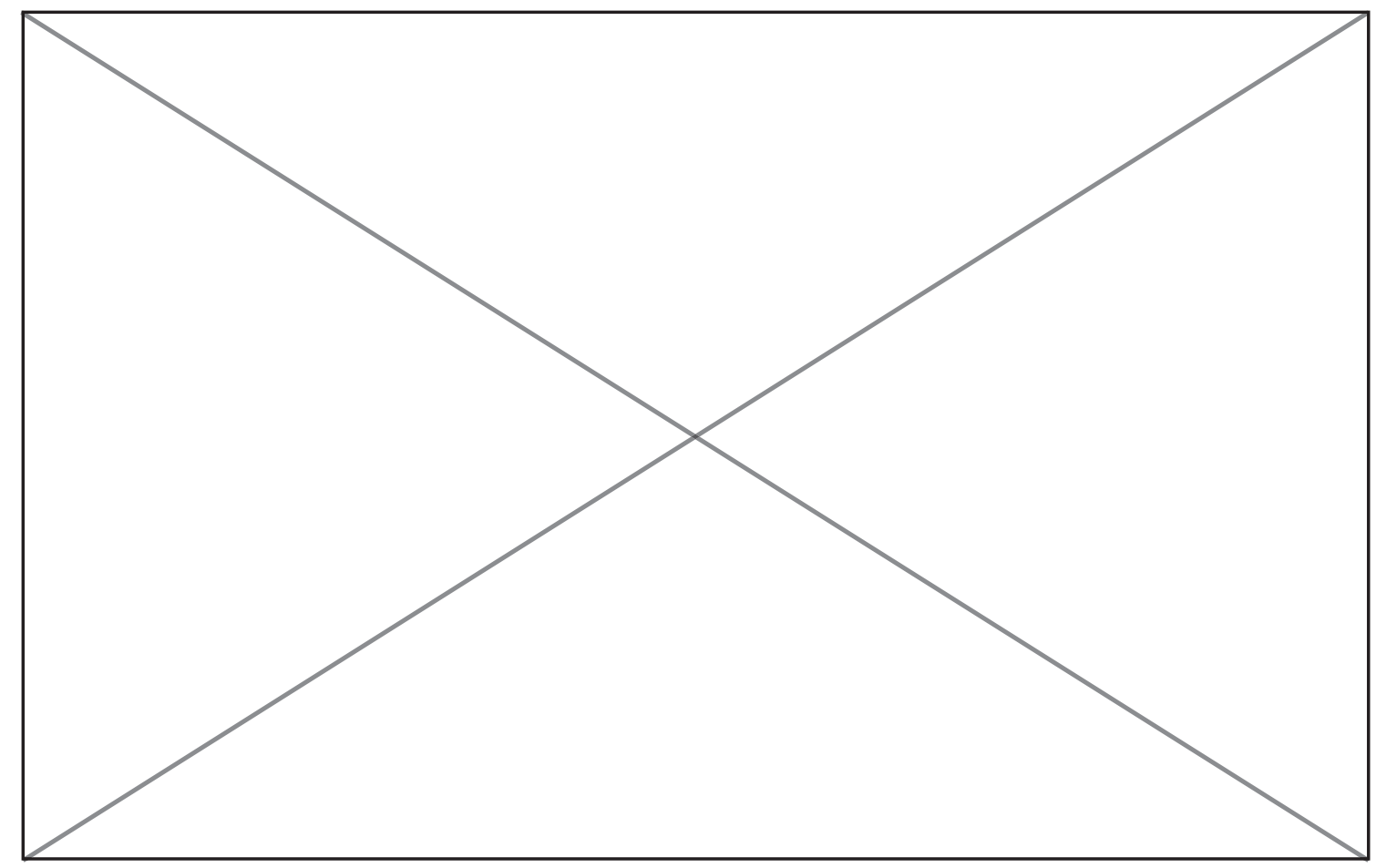

Figure 5.14 Xiang Yun 祥云 (Auspicious Clouds)

This photo shows that auspicious clouds is a commonly design in the pattern. It has good meaning for "luck" or "fortune". 


\section{Concept Development}
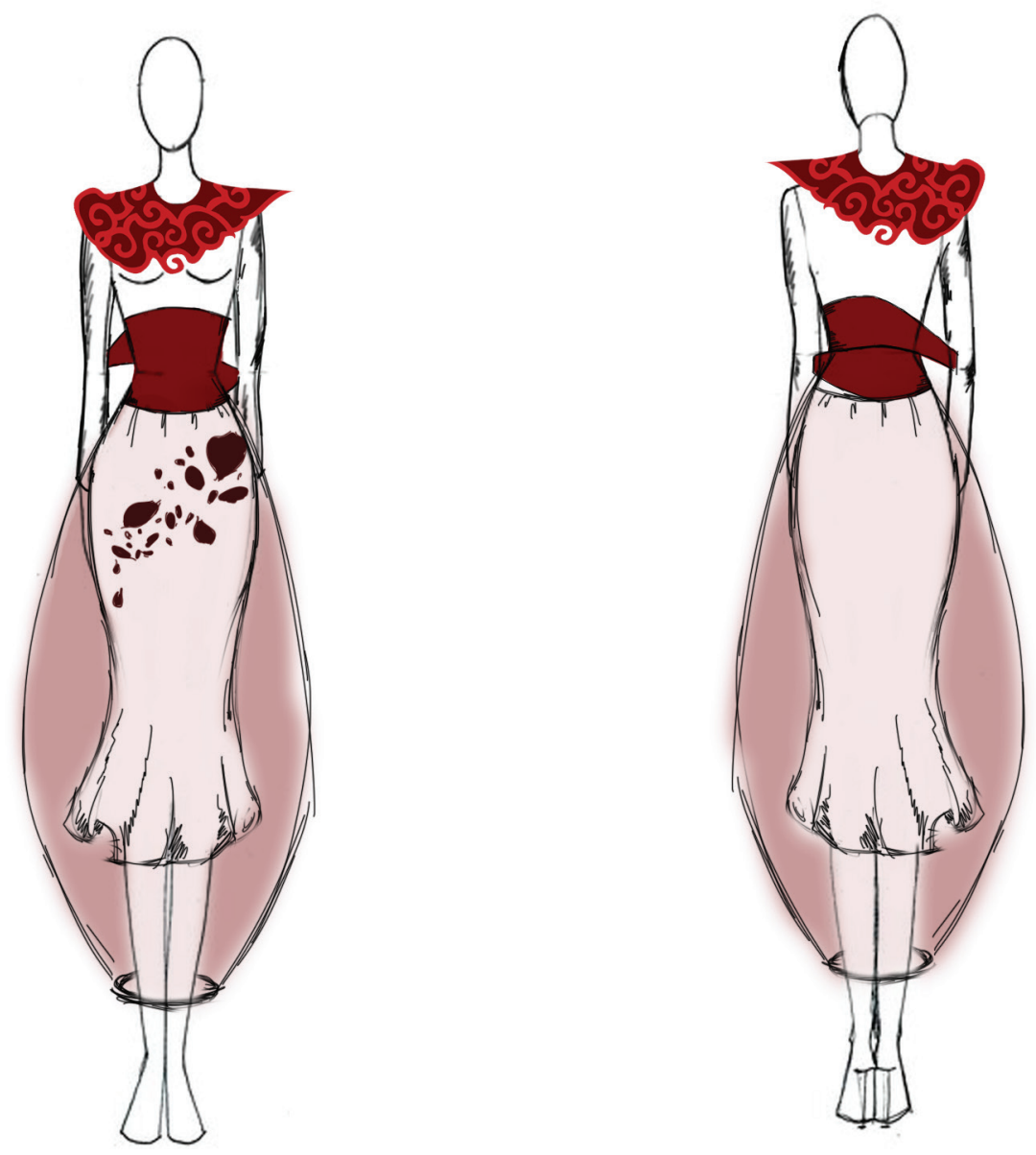

Figure 5.14

This concept improvement is based on concept C combined with more historical research. White and red colors continue to represent Western and Chinese cultures respectively. Again, the white fabric forms the inner dress, with red outside. The white skirt looks really easy to walk in. However, the model cannot walk fast or with big steps. I wanted to make two main points with this garment: 1) Chinese women feel restricted and want freedom of marriage. 2) Through interacting with audience, the garment shows the relationship between Chinese society and women who do not want to get married. The corset looks like a traditional Chinese wedding dress' belt. The back of the corset is connected to the arms. This means when the model moves her arms, she feels tight and uncomfortable. This is the final concept I pursued for my garment design. 


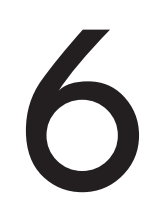

Physical Experiments 
Fabric
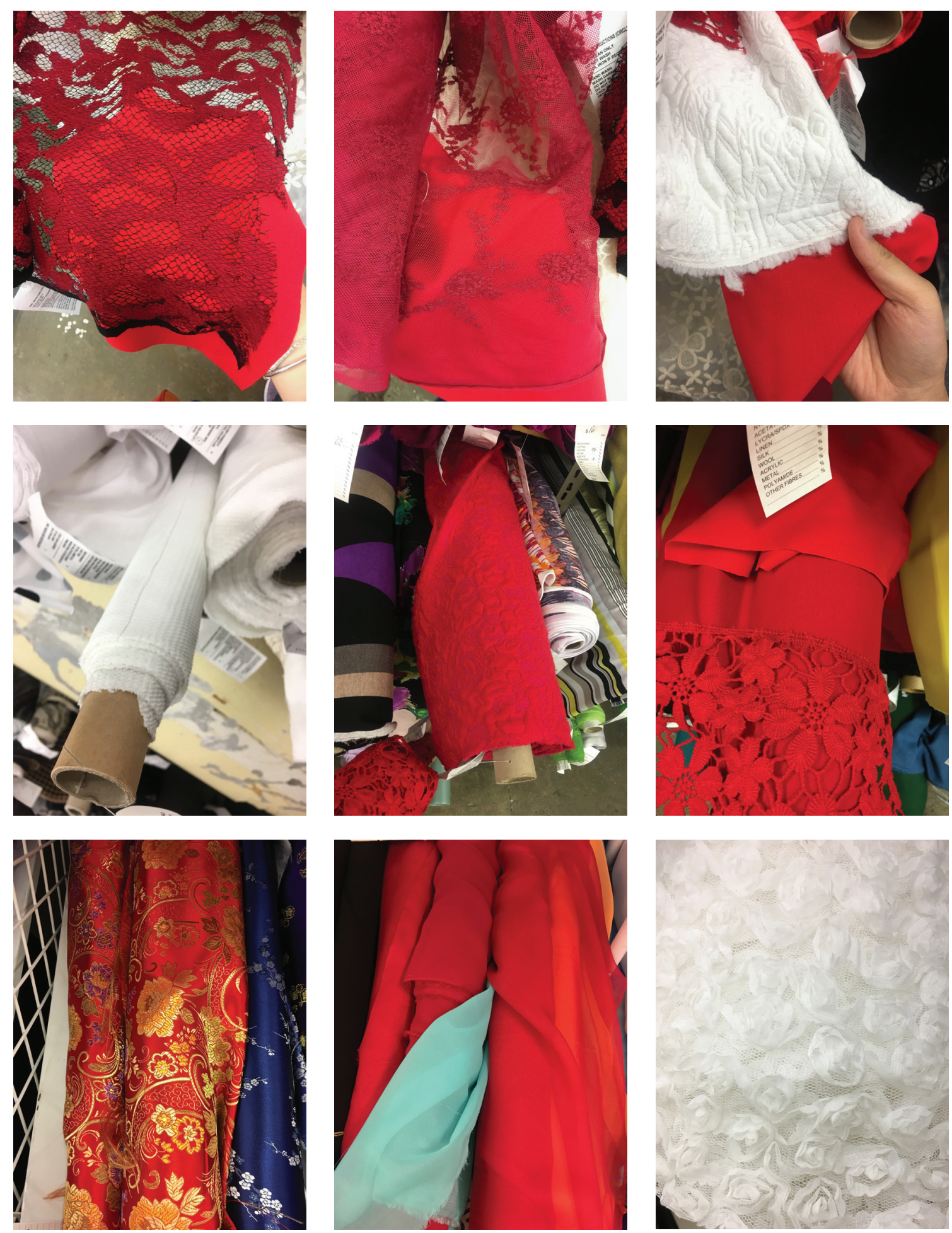

Figure 6.1 


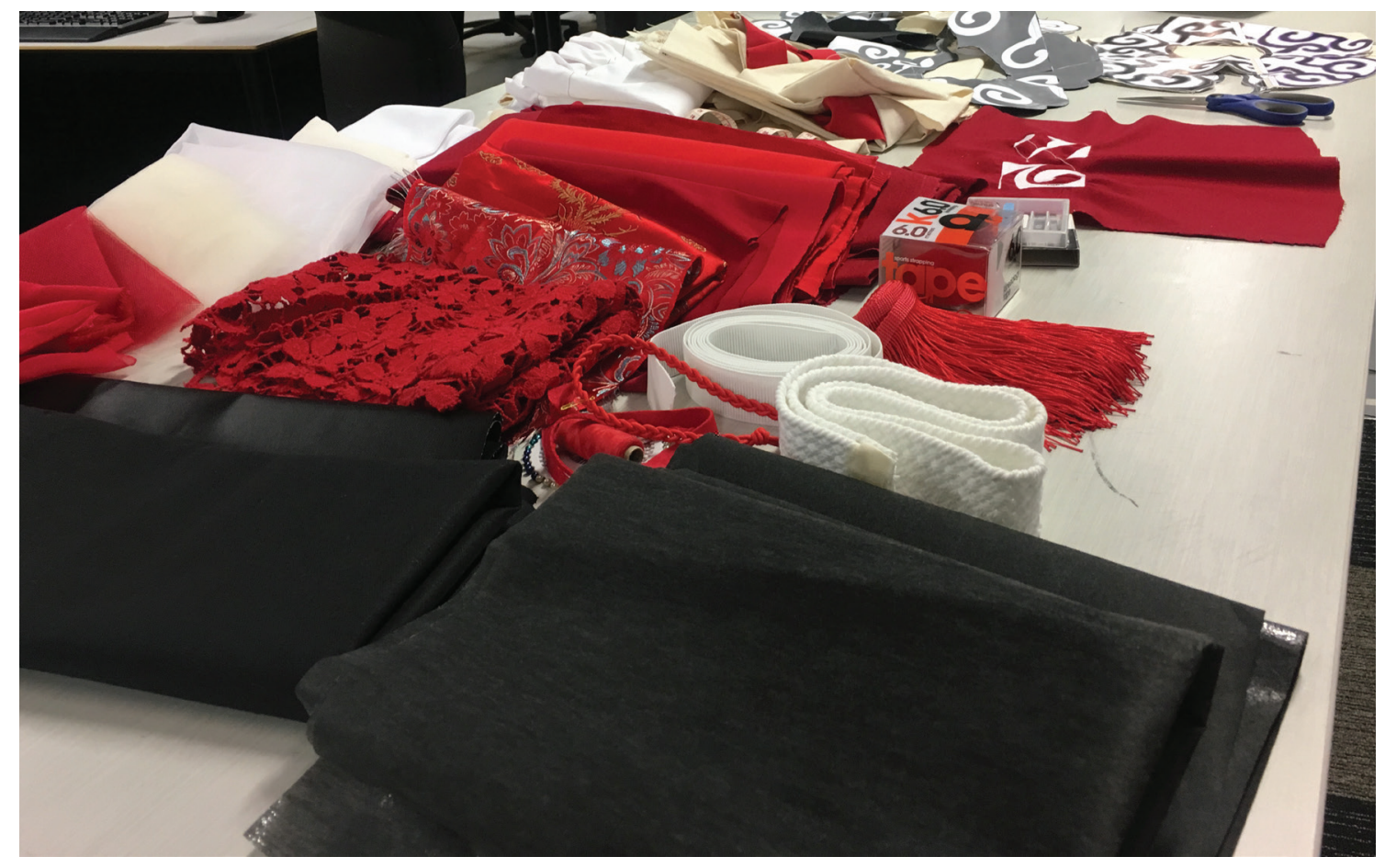

Figure 6.2

Again, my garment will use red and white to represent Chinese and Western weddings. The garment incorporates embroidery, pattern and red flowers that are elements in traditional Chinese weddings. White flowers and voile are elements in Western weddings. I compared different types of fabric to design the garment's aesthetics and comfort. 


\section{Prototype}

\section{Prototype 1}

This concept has two parts, top and skirt. The top is tight and has long sleeves.

The skirt is a wrap skirt that is tapered, so the model cannot walk too fast.

Because this was the first prototype, I did not think about the meaning of the colors. This prototype mainly focuses on making the model feel constrained.

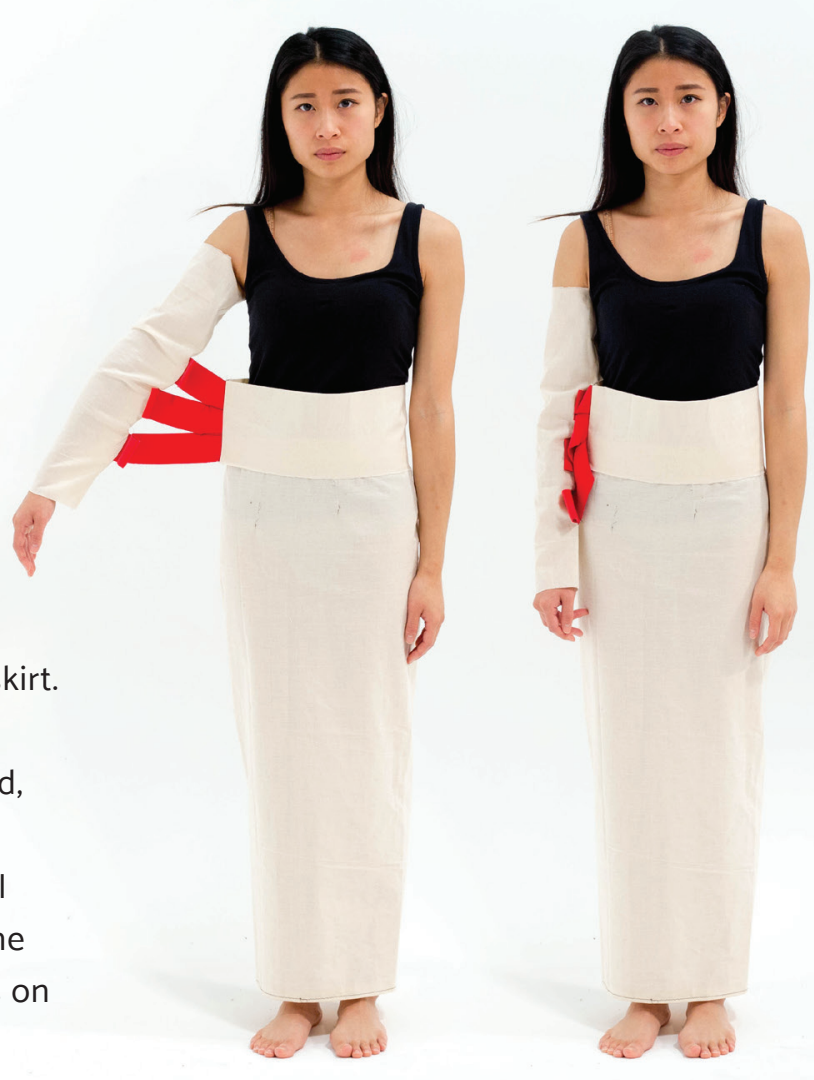

Figure 6.3
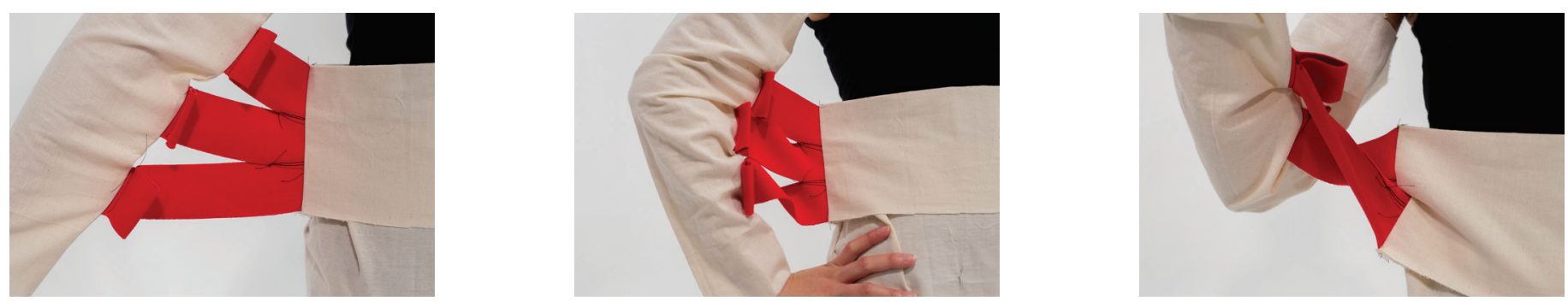

Figure 6.4

These three photos show how the connecting part stops the model from moving her arm too wide. This connecting part limits the model's movement. The model feels it pulling when she moves her arm. However, this design does not look aesthetically pleasing. 


\section{Prototype 2}

The second prototype improves the skirt and the elastic connecting strap. This connects the arms behind the back. The skirt combines a white wrap with a red voile outside layer.
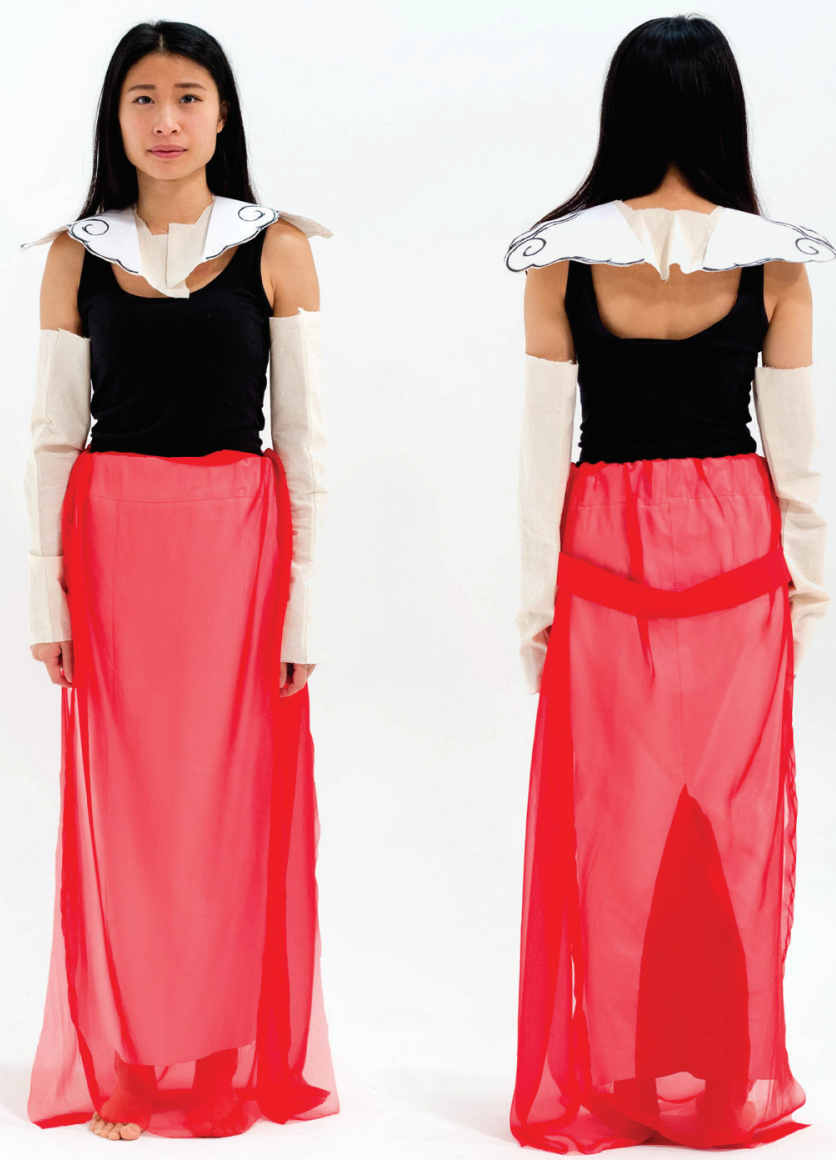

Figure 6.5

Model moves her arms from the right to the left.

Figure 6.6
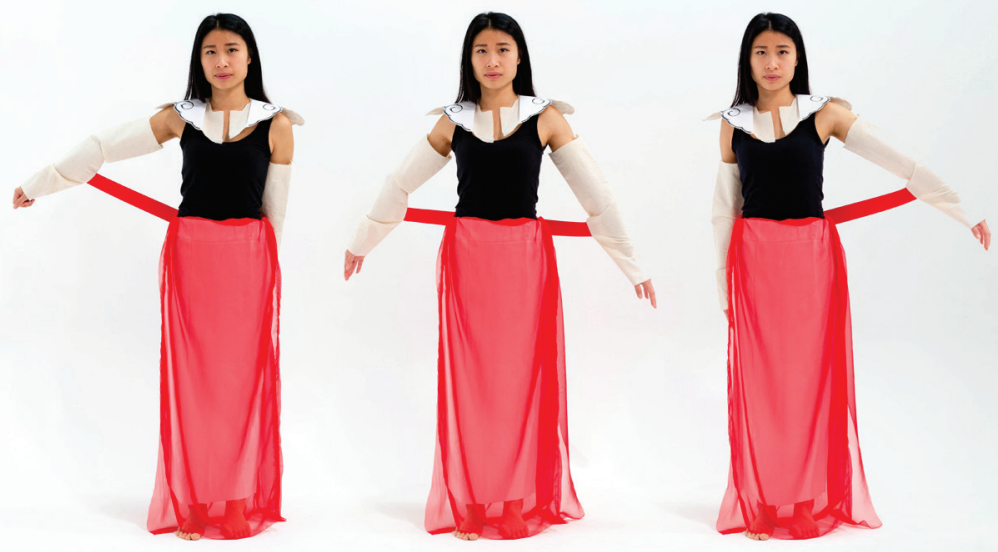

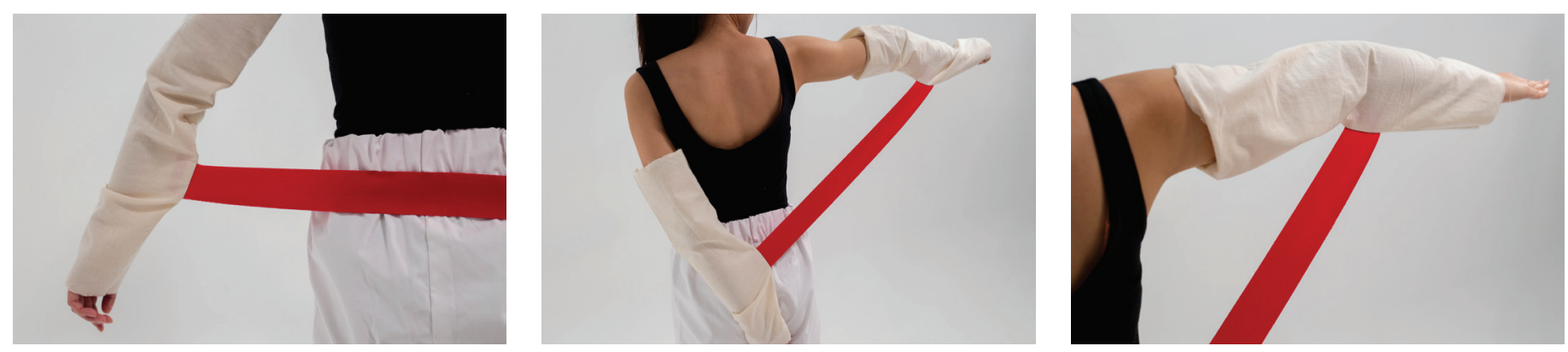

Figure 6.7

I used the same elastic band as the first prototype to make the strap. One elastic strap is less constraining than the three elastic straps from the first prototype. The model found it easier to move in the new garment.
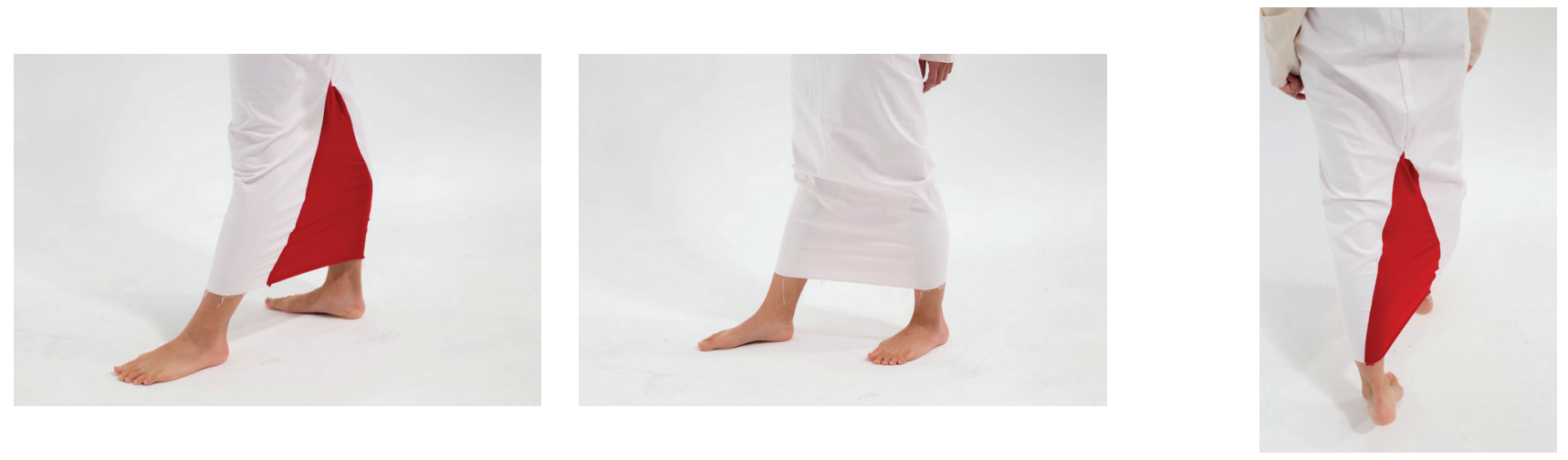

Figure 6.8

The skirt uses two different types of fabric. The red fabric triangle at the back of the skirt can stretch, but white cannot. The stretch fabric gives people a sensory illusion that it is easy for the model to walk.
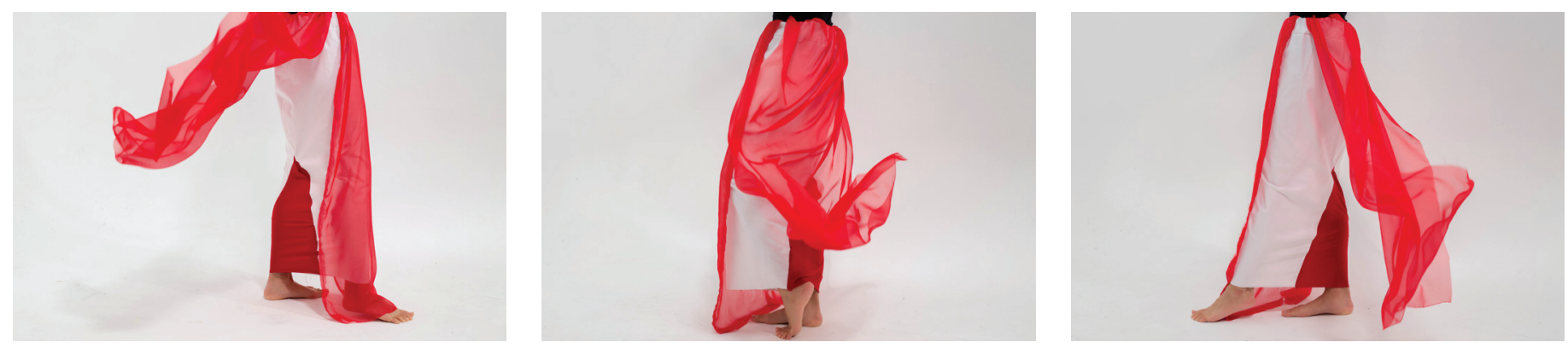

Figure 6.9

These photos show the skirt constraining the model's movements. 
Based on concept C, I used red voile to make the outside layer on this prototype. When the model walks, people can still see the white wrap skirt.
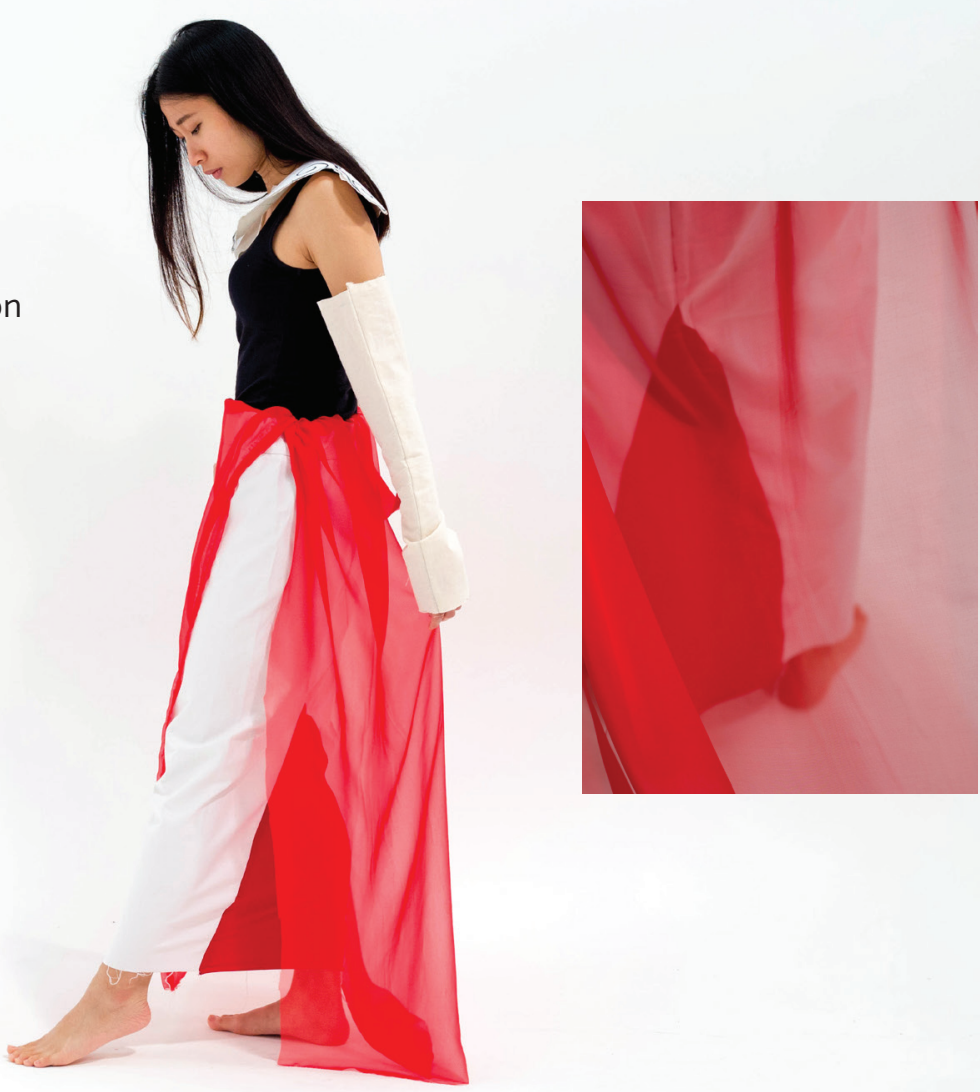

Figure 6.10 


\section{Prototype 3}

The third prototype improves the elastic strap by circling it around the waist to connect the two arms. The strap now tightens around the model's body when she opens her arms.
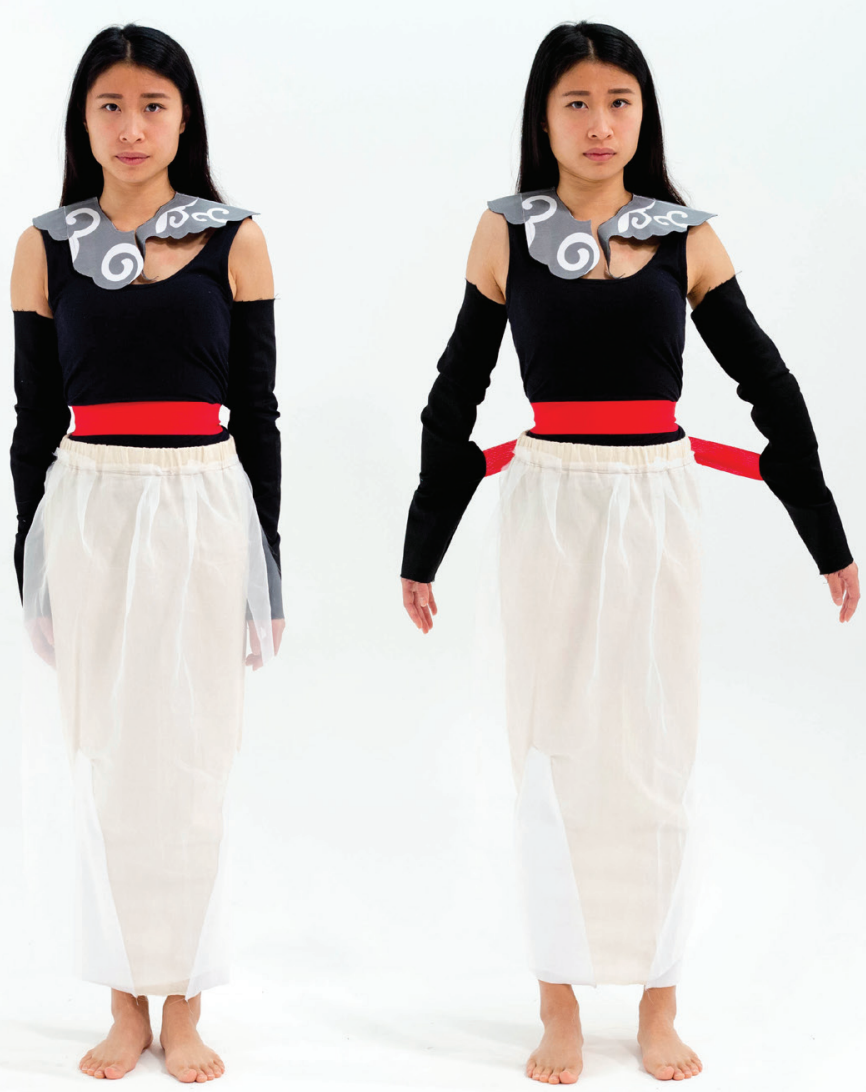

Figure 6.11 
By circling around the body, the elastic band makes a cross shape at the back.

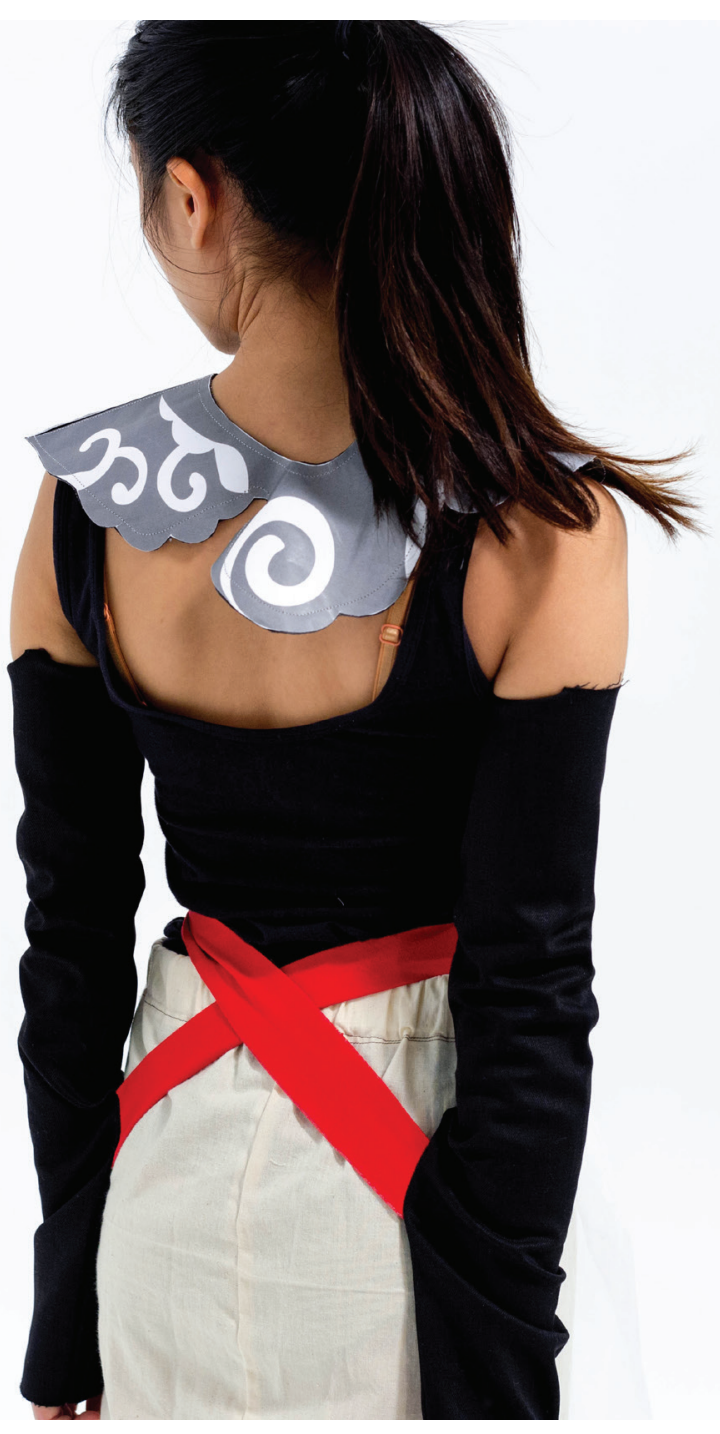

Figure 6.12 

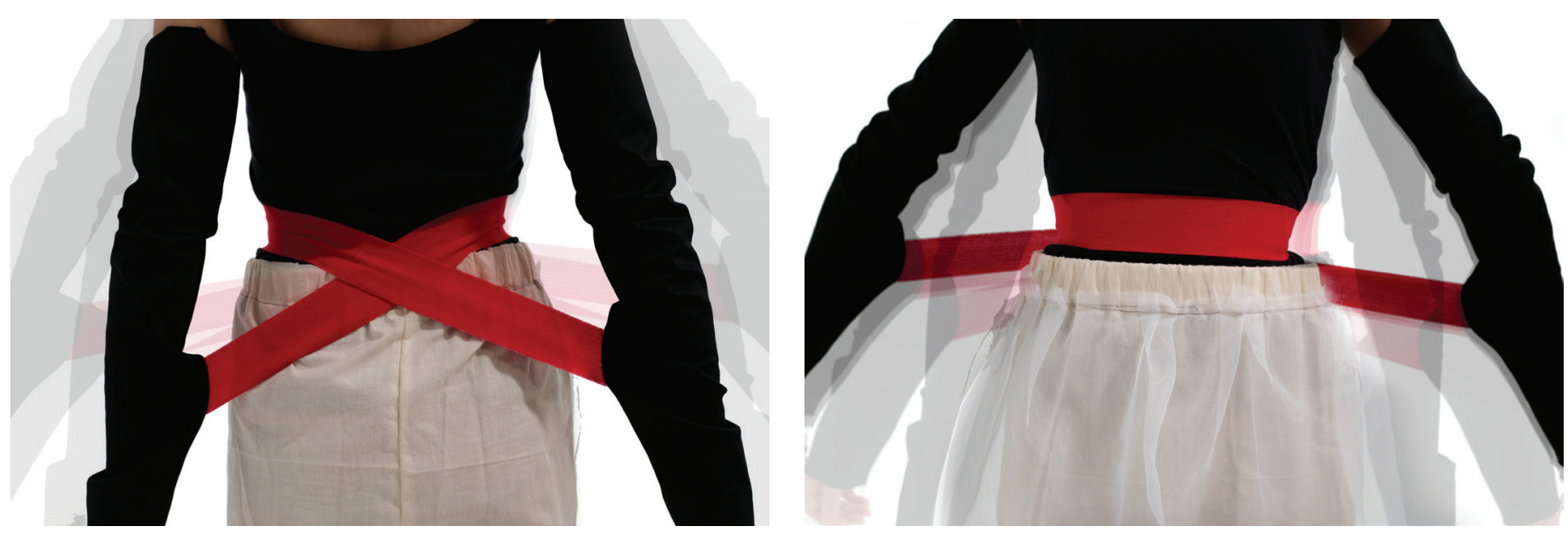

Figure 6.13

This group of photos shows the model's waist changing according to when she opens her arms. The strap tightens when she opens her arms wider. However, the model still felt too free to move compared to my aims.
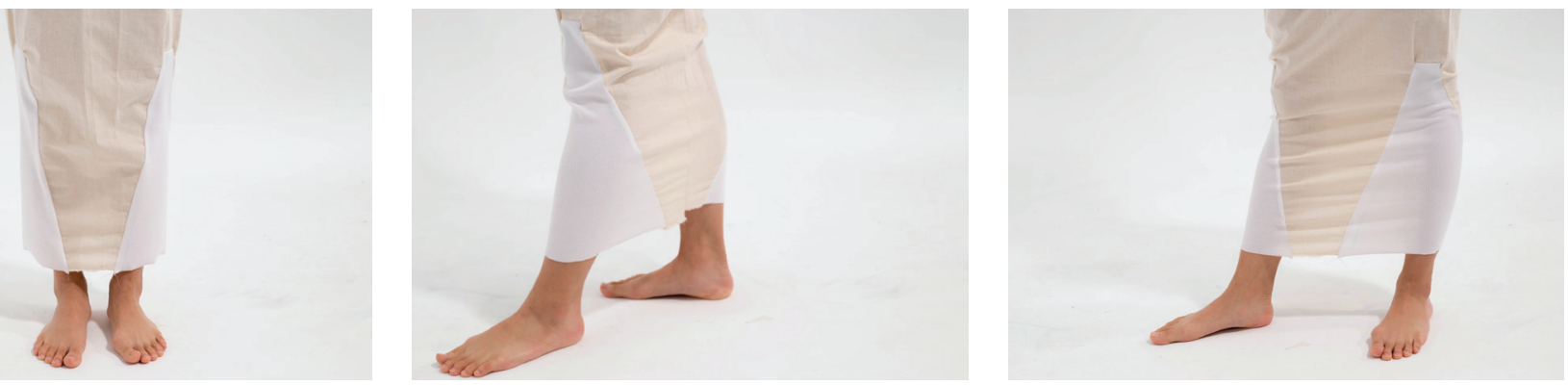

Figure 6.14

This time, the stretch fabric is on both sides of the skirt. This design is more interesting and easier to walk in than prototype 2 . This skirt represents Chinese tradition. The white triangles represent the West's influence on China. This includes greater individual freedom, here represented by greater (but still limited) freedom to walk. 


\section{Prototype 4}

These photos show the fourth prototype's front and back. In order to most effectively express my concept, I made the outside skirt white, and the inside red. The red and white color swap makes the skirt look more like a Western wedding dress. I used red for the inner skirt because traditional Chinese culture deeply influences people's minds.
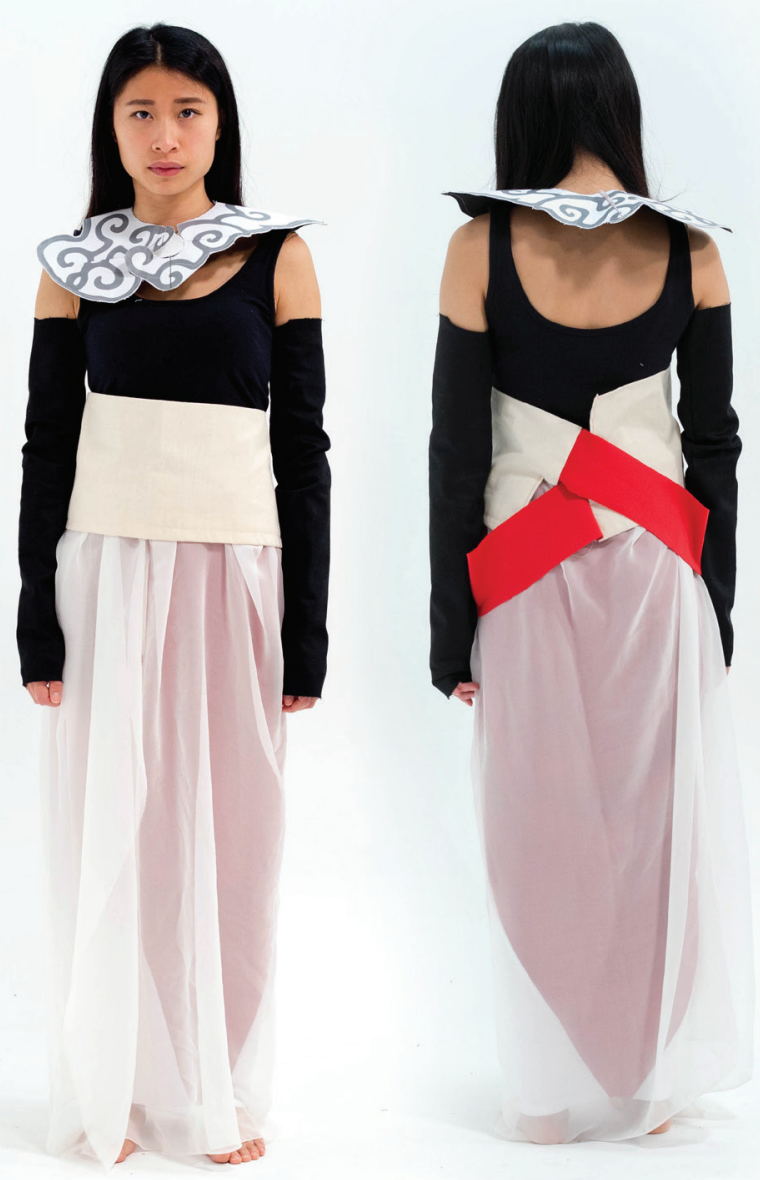

Figure 6.15 


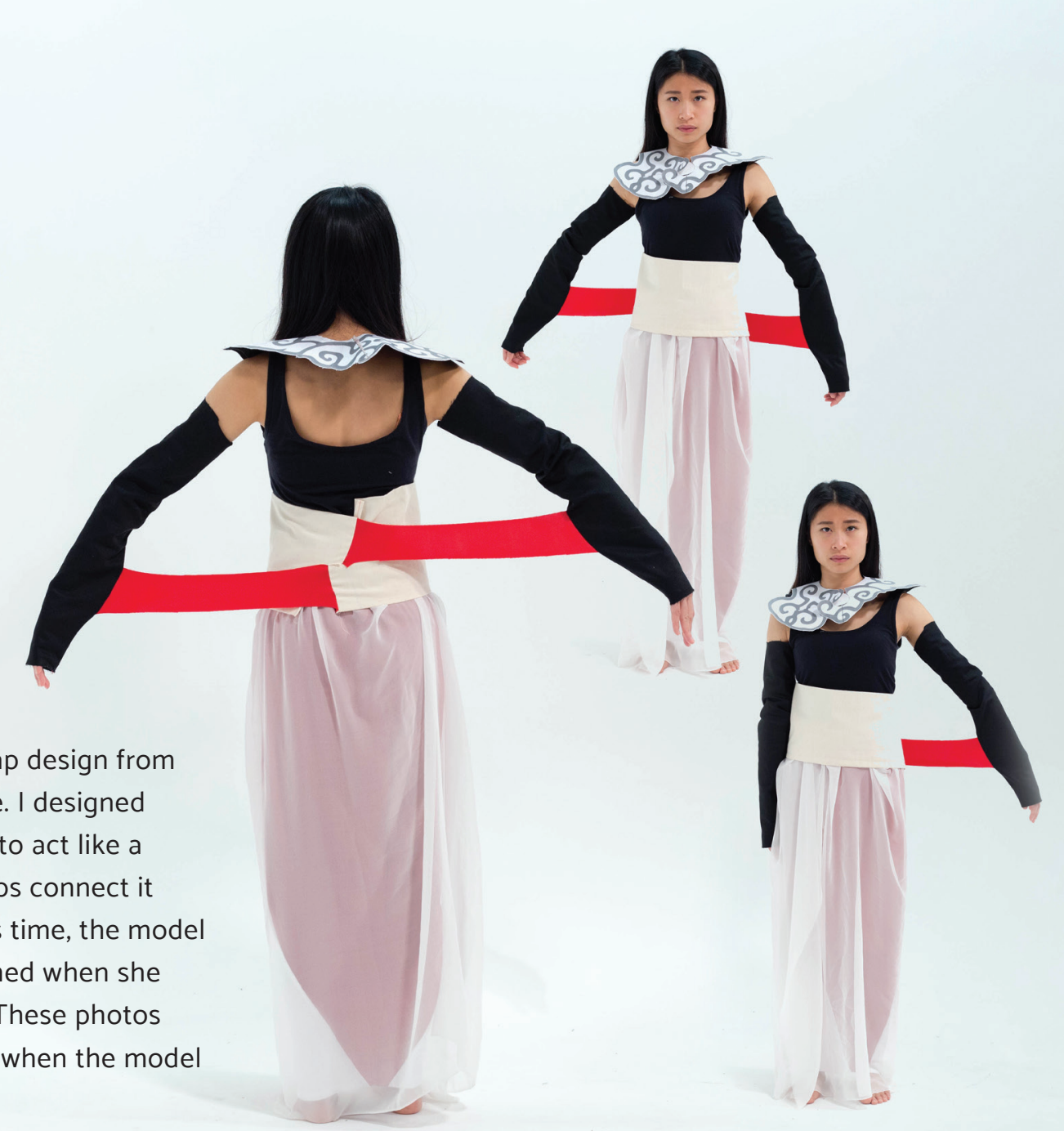

Figure 6.16 


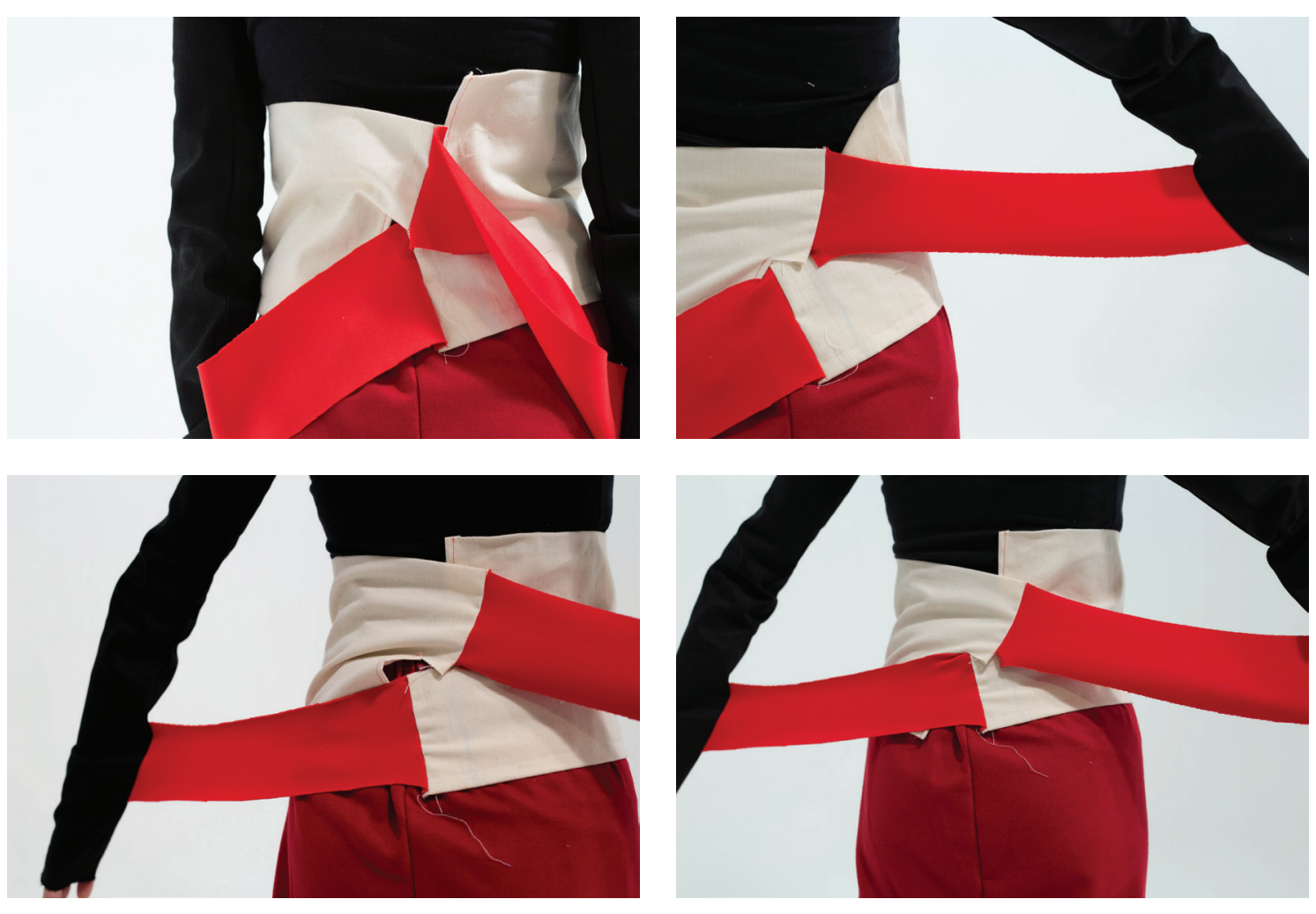

Figure 6.17

The back of waist is cut open. The top elastic strap connects to the right arm, and the bottom one connects to the left arm. When the model opens her arms, the waist will tighten. These photos show the waistband contracting when the model opens her arms.
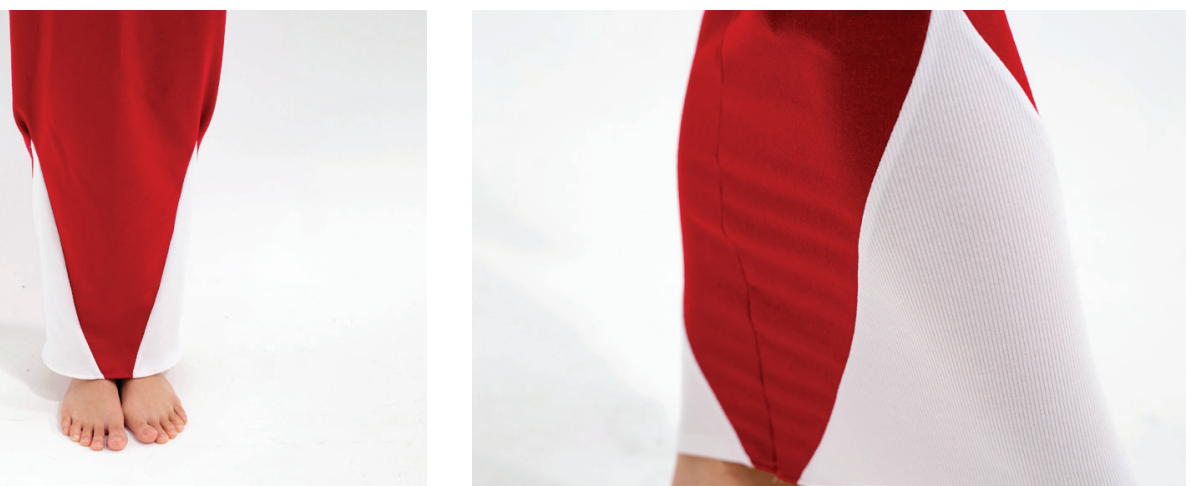

Figure 6.18

Above, the skirt constrains the model's movement. The skirt design includes a non-stretch red fabric and a stretchable white fabric. This represents the way that traditional Chinese culture constrains Chinese women's right to freedom of marriage, but Western feminism culture gives them hope. 


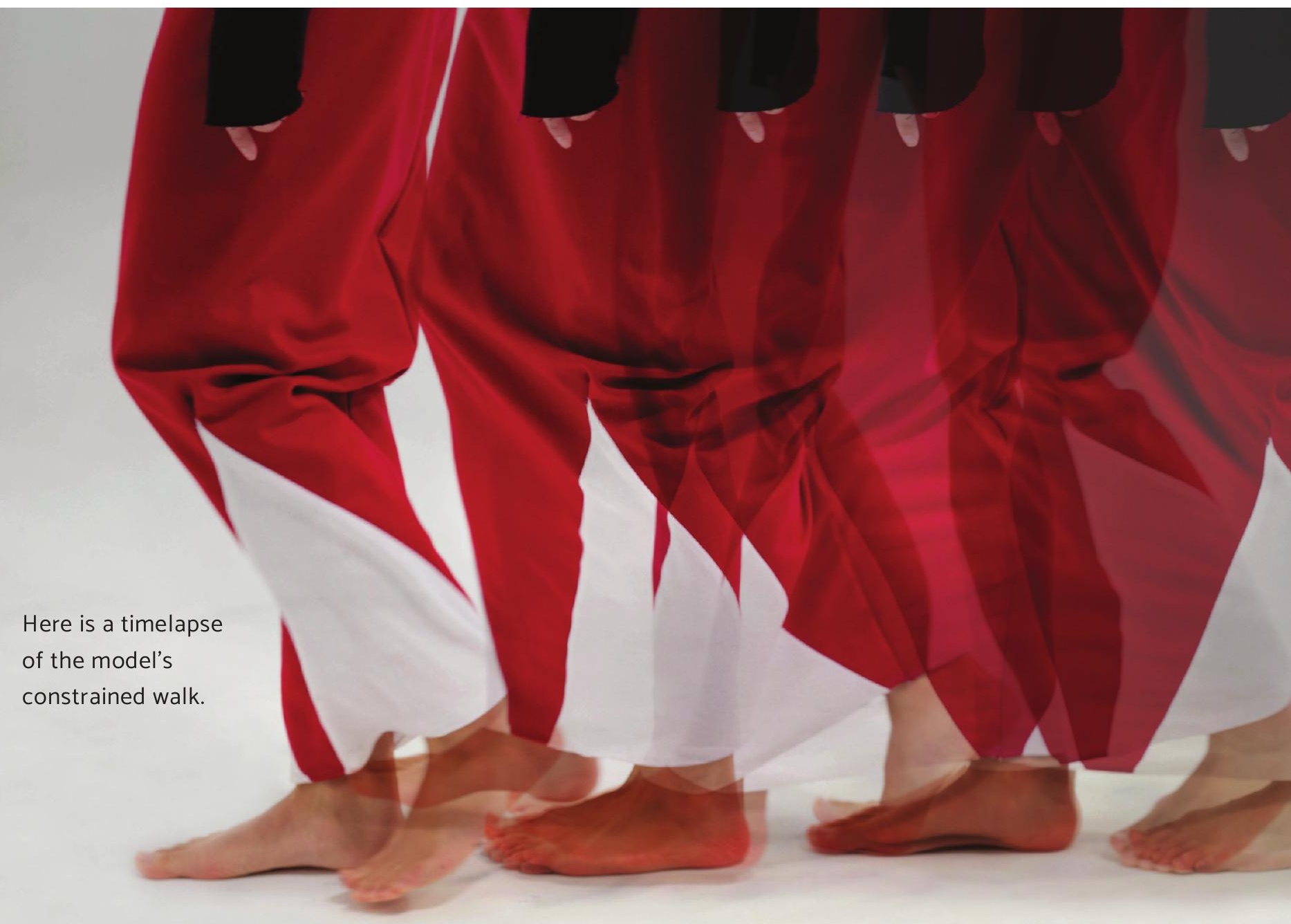

Figure 6.19 


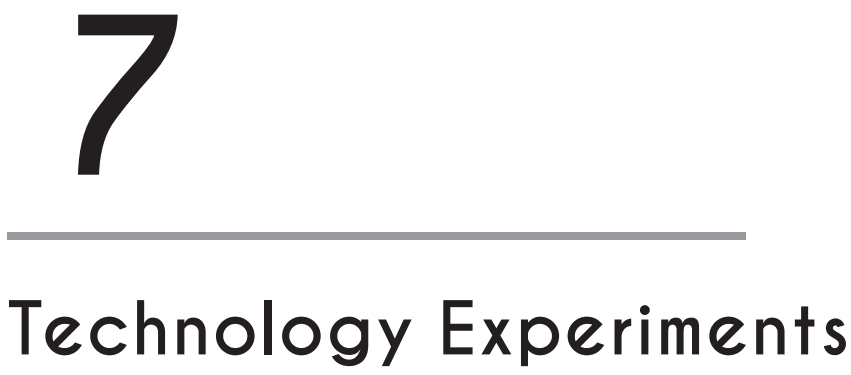


My design goal is to create an interactive garment to reflect that women suffered injustice in Chinese marriage. The constricting dress represents this constraint by Chinese culture. Due to this injustice, women want to feel free through movement. Two particular inputs are suitable to reflect this feminist issue: Stretch sensors, and distance sensors. Stretch is already a function of my garment, because it constrains the model's movement. The distance between the audience and the garment represents how people should give women space. Women deserve gender equality and freedom to choose whether or not to marry. The stretch sensors will connect to the LED lights. The petals will be controlled by the distance sensors. My garment will uses LED lights and petals as expressive outputs. Investigate of different material to achieve my garment, there are some technology material research:

\section{Input}

\section{Stretch}
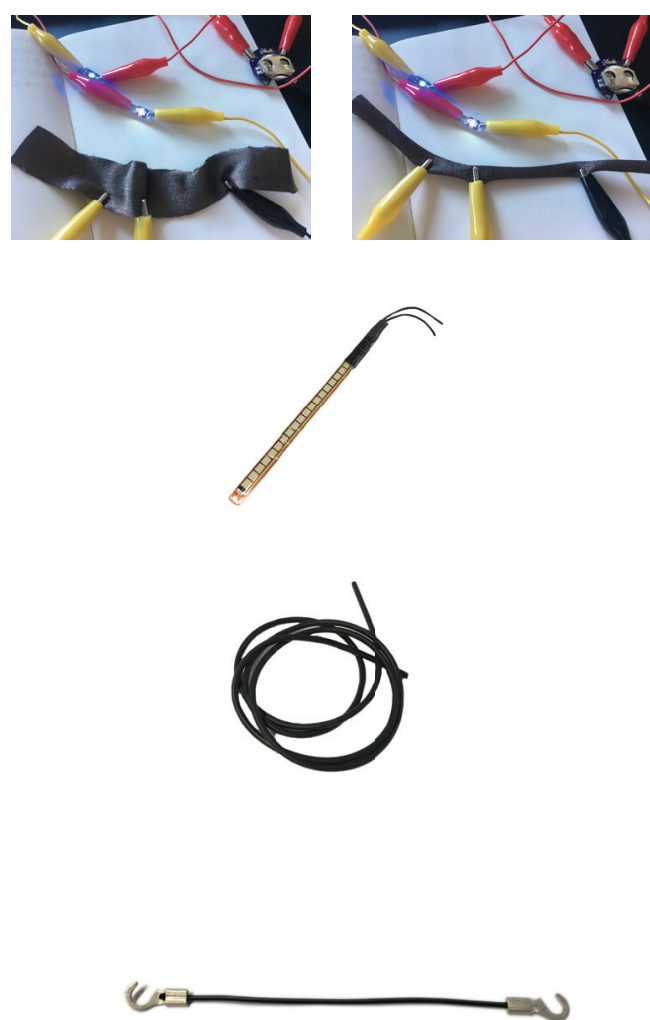

\section{Conductive Fabric}

The advantage of conductive fabric is that it can easily connect the LEDs, and it can stretch. But it cannot return to its original shape.

\section{Flex Sensor}

The sensor responds when it flexes. These sensors do not stretch, so they do not suit my garment's function.

\section{1m Flexible Stretch Sensor}

This flexible sensor is conductive and stretchable. The resistance gradually increases when the sensor is stretched. This sensor is suitable for my garment, and gave good input response. However, the sensor breaks when stretched too much.

\section{2" Flexible Stretch Sensor}

I tested this one-meter flexible stretch sensor, and changed the sensor size to 2". This is suitable for my garment, and hides well on the fabric.

Figure 7.1 
Distance

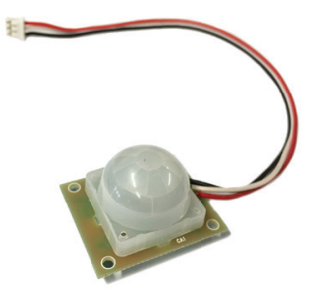

PIR Motion Sensor

Motion sensor uses infrared to detect nearby motion. However, it can only detect movement, it cannot detect distance.

\section{Sharp GP2YOAO2YKoF}

Sharp's infrared sensor detects distance.

Considering the form factor, this sensor is not suitable to use in my garment.

\section{VL53LoX Distance Sensor}

This distance sensor is simple and small. It also uses infrared. It gets accurate results about its targets' color and surface. It can measure objects from 0.03 to 2 meters away. 


\section{Output}

\section{LED Light}

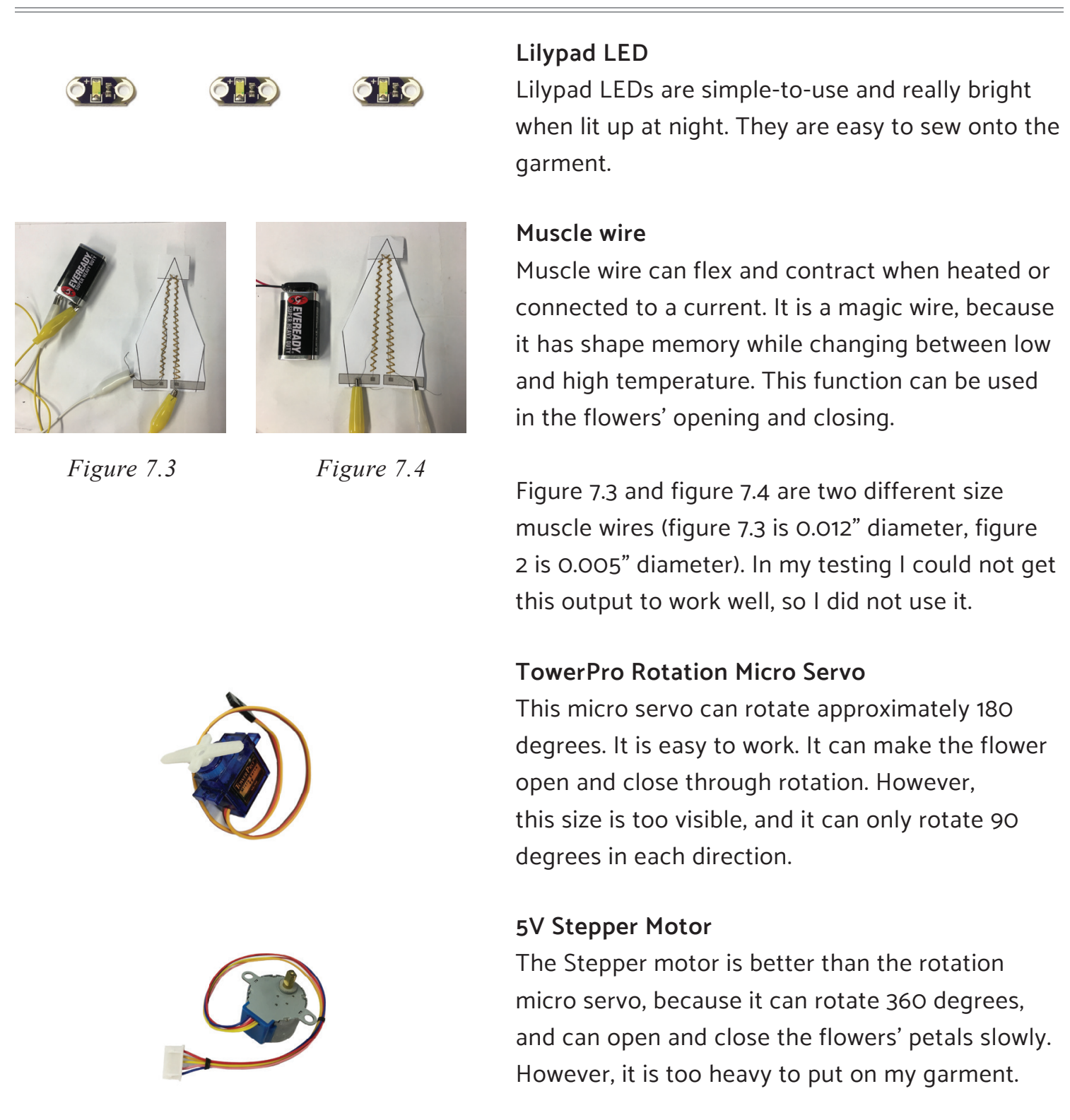

Figure 7.5

According to this research and comparison of material technologies, my garment will use 2" flexible stretch sensors as inputs for the garment's lights, and VL53LOX distance sensor to detect the audience's proximity. I will use LED lights to create various expressions of the garment. 
Final Design 
I have based my design on my experiments and theoretical research, including a questionnaire about the perception of women's role in China. I designed Zi. Force, a responsive wearable garment, to bridge these experiments. The word "Zi” translates to Chinese as “自”. It has two expressions in Chinese: One is “myself” (自己), another is “freedom”(自由).

\section{Zi. Force Design}

Zi. Force, my final garment, re-interprets the traditional Chinese wedding dress ("Qun Kwa" and "Cheongsam"), and combines it with Western wedding dresses. Again, white and red colors continue to represent Western and Chinese cultures respectively. Zi. Force has three parts, which are the shoulder cape, the blouse, and skirt. Through my research, I found that Western culture gradually influenced Chinese people's lives due to an opening of Chinese society. In modern Chinese wedding ceremonies, people not only wear the traditional wedding dress, more often they wear the white Western wedding dress. However, traditional culture still affects people deeply, such that many people think unmarried women are incomplete. Therefore, Zi. Force's overall design concept looks more like a Western wedding dress. The inner red skirt represents traditional Chinese culture's influence over people's minds. The petals are distributed in inner skirt from the top left to the right back. The white and red color petals represent that flowers are motifs of best wishes in both Western and Chinese weddings.
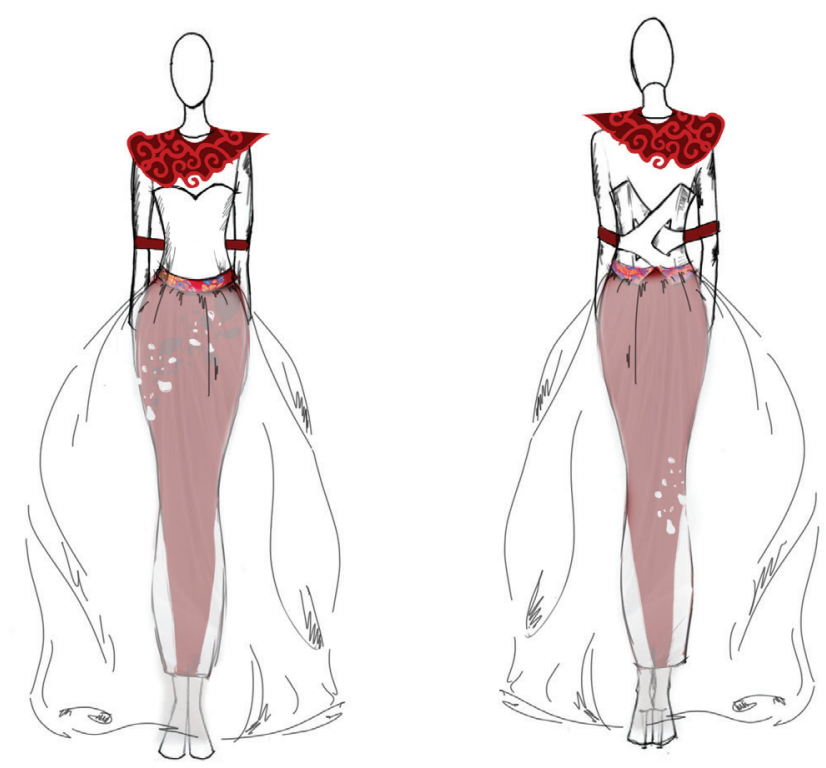

Figure 8.1 

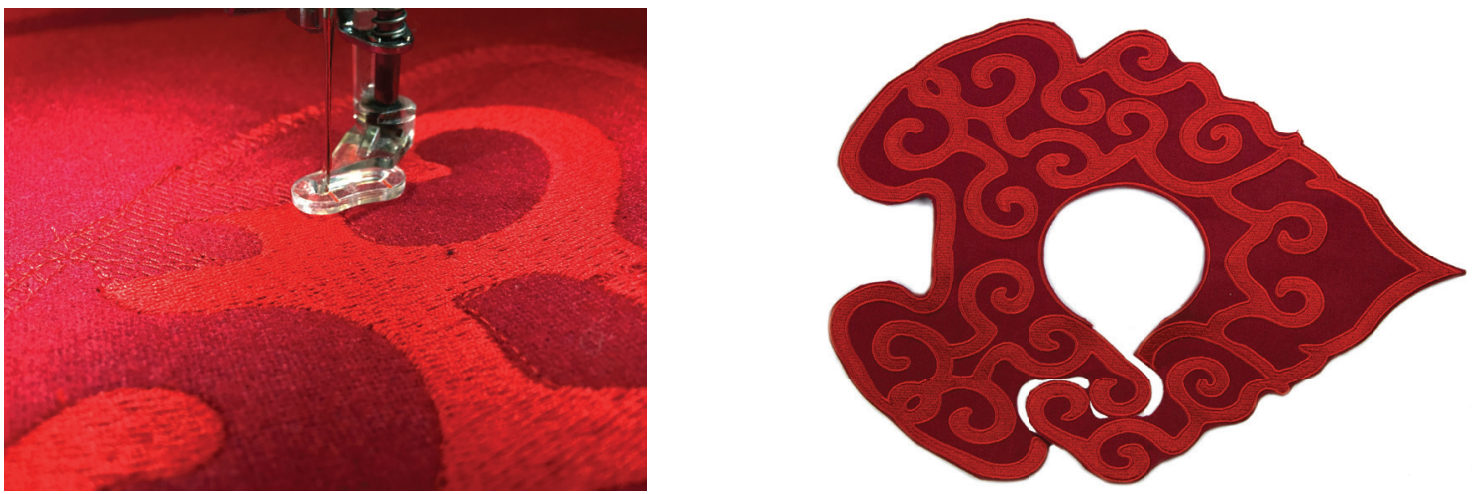

Figure 8.2

Creating the final shoulder cape: the pattern is embroidered because it embodies traditional Chinese craft and art. My shoulder cape is inspired by Wo.Defy's (Ip, Chung, Lee \& Schiphorst, 2014) broadened shoulder. The broadened shoulder design in Wo.Defy is characteristic of male fashion. It represents the Self-Combing Sister's independence. My shoulder cape uses different shapes on the left and right sides. The left side represents women and the other represents men.
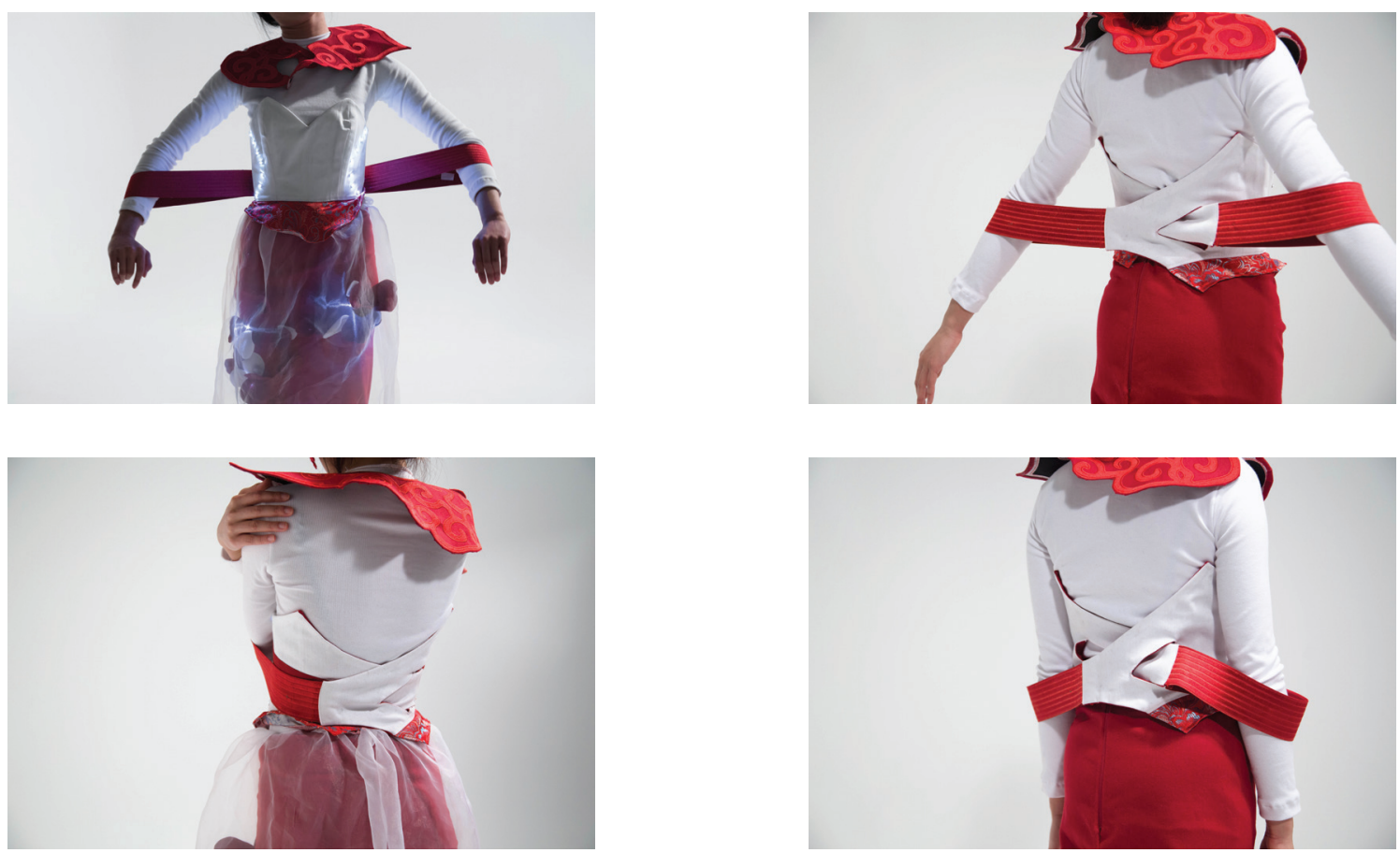

Figure 8.3

The back of corset is made up of that two triangles are intersecting each other. The top elastic strap connects to the right arm, and the bottom one connects to the left arm. When the model opens her arms, the waist will tighten. Red elastic straps control the corset's LEDs. The left arm controls corset's right side, the right arm controls corset's left side. 

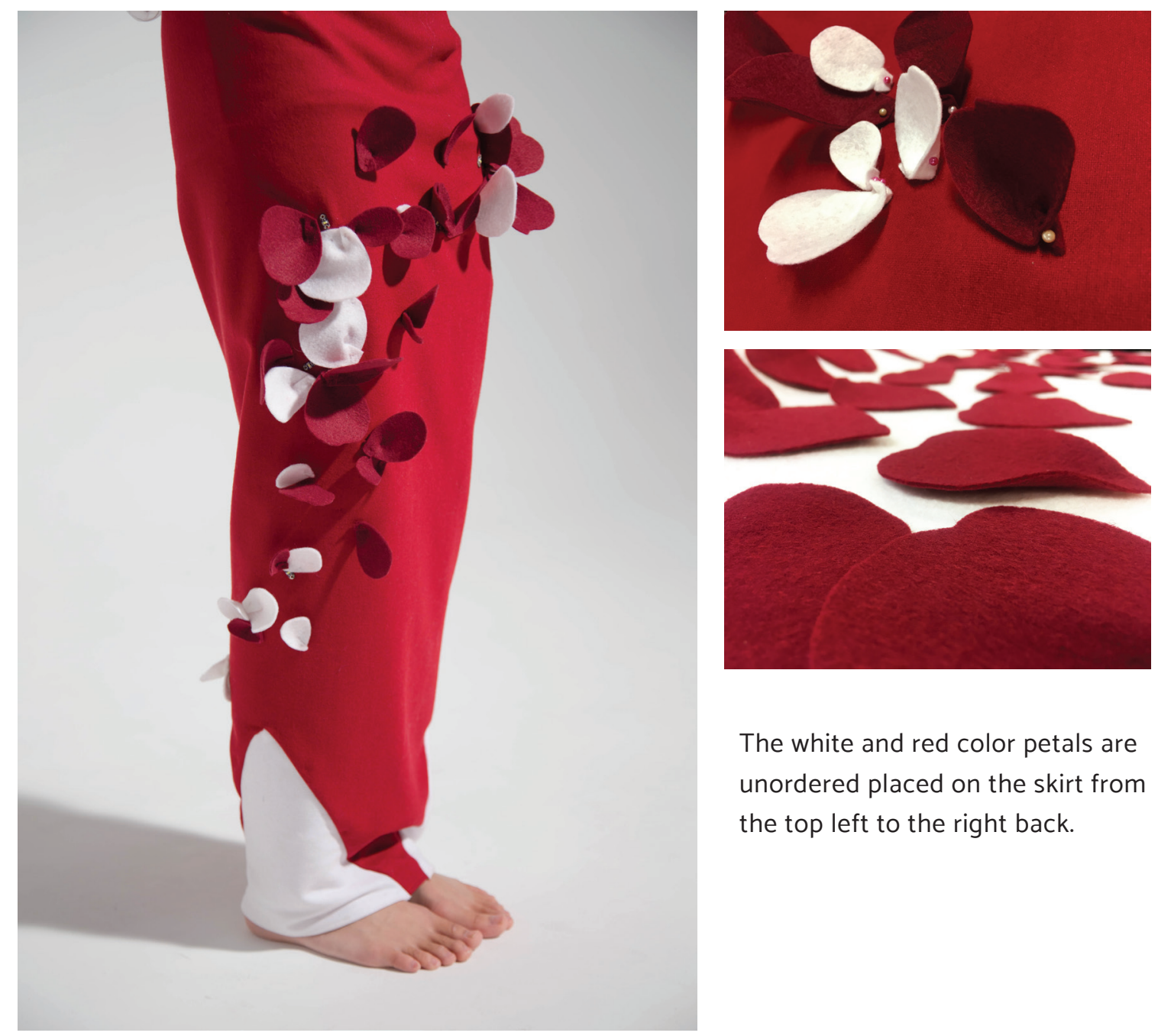

The white and red color petals are unordered placed on the skirt from the top left to the right back.

Figure 8.4 
Figure 8.5

The inner skirt is designed to constrain the model's movement by the small shape of the bottom, and the most part of the non-stretch fabric. On the bottom of the skirt has a small part of the stretch fabric that represented by the greater individual freedom to walk, but still move a small step. 
Figure 8.6

The model maintains a standing in the crowd. The audience will walk around the model. The LEDs on the skirt is kept bright. When audience close to the model, the lights will start flashing, like a nervous signal from the model. 
Distance Circuit

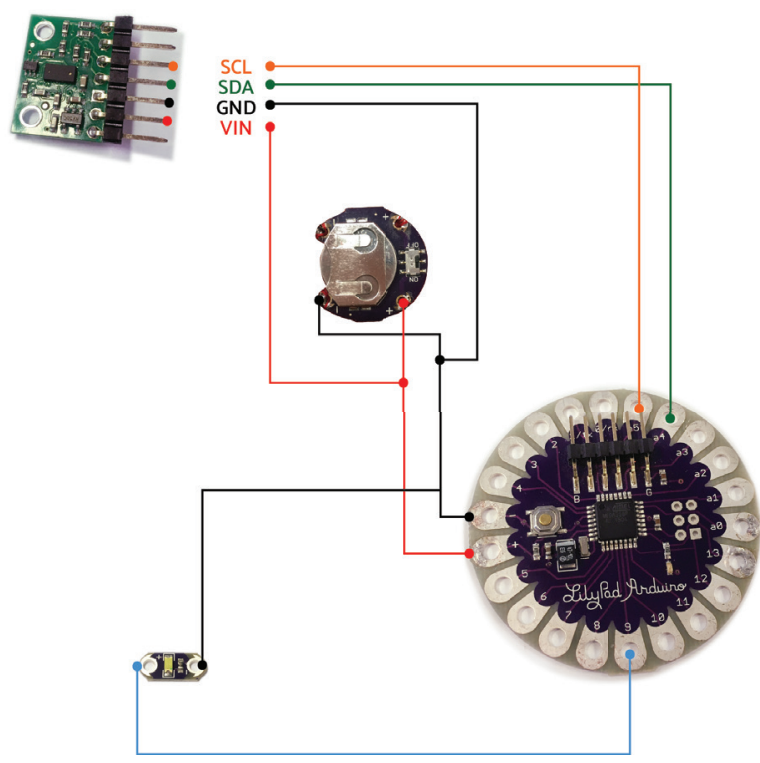

Stretch Circuit

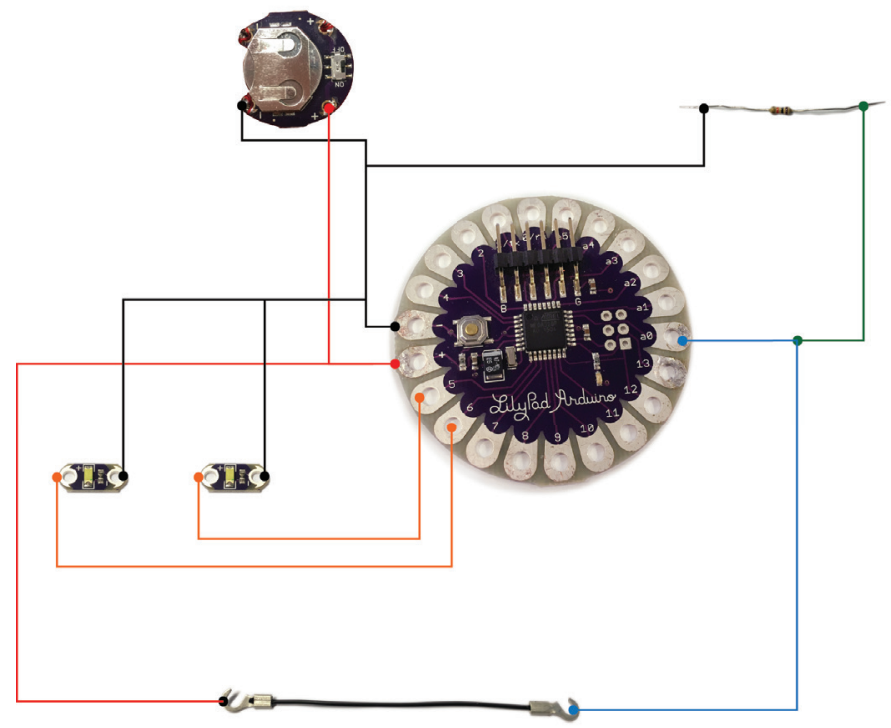

Figure 8.7 


\section{Circuit Diagram}

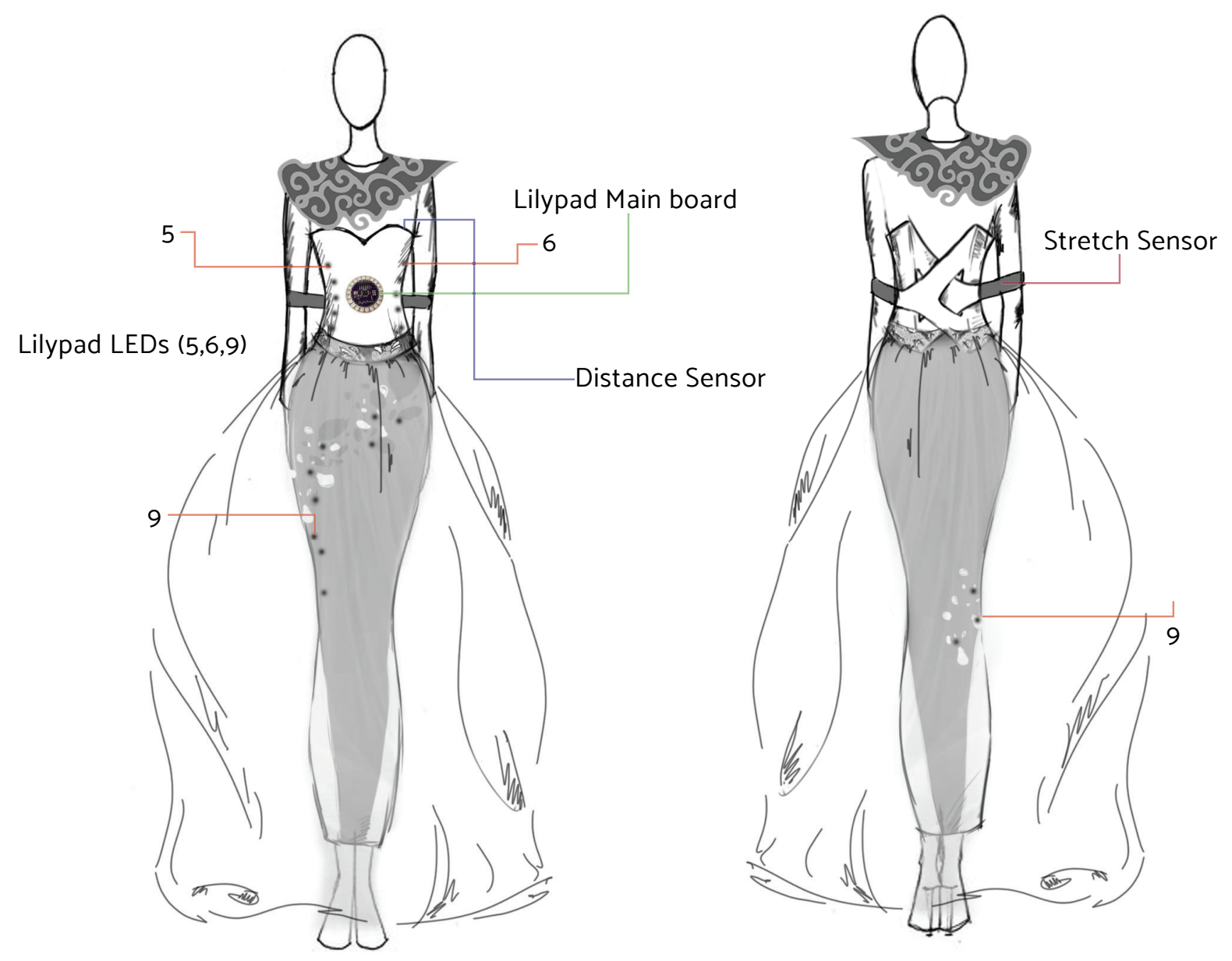

Figure 8.8

The Lilypad Arduino board on the centre of the corset collects data from input sensors. This data is the model's movement, and their distance from the audience. The Lilypad board then organizes the outputs. I put LEDs on the corset. These lights fade in when the model opens her arms or walks. The lights on the petals will flash when the audience is close to the model, and will stabilize when the audience is far.

On the diagram above the numbers 5, 6, and 9 represent the PIN numbers in the Lilypad main board, which connects each LED light. PINs 5 and 6 connect the lights to the stretch sensor, and PIN 9 connects the lights to the distance sensor. 


\section{Zi. Force}

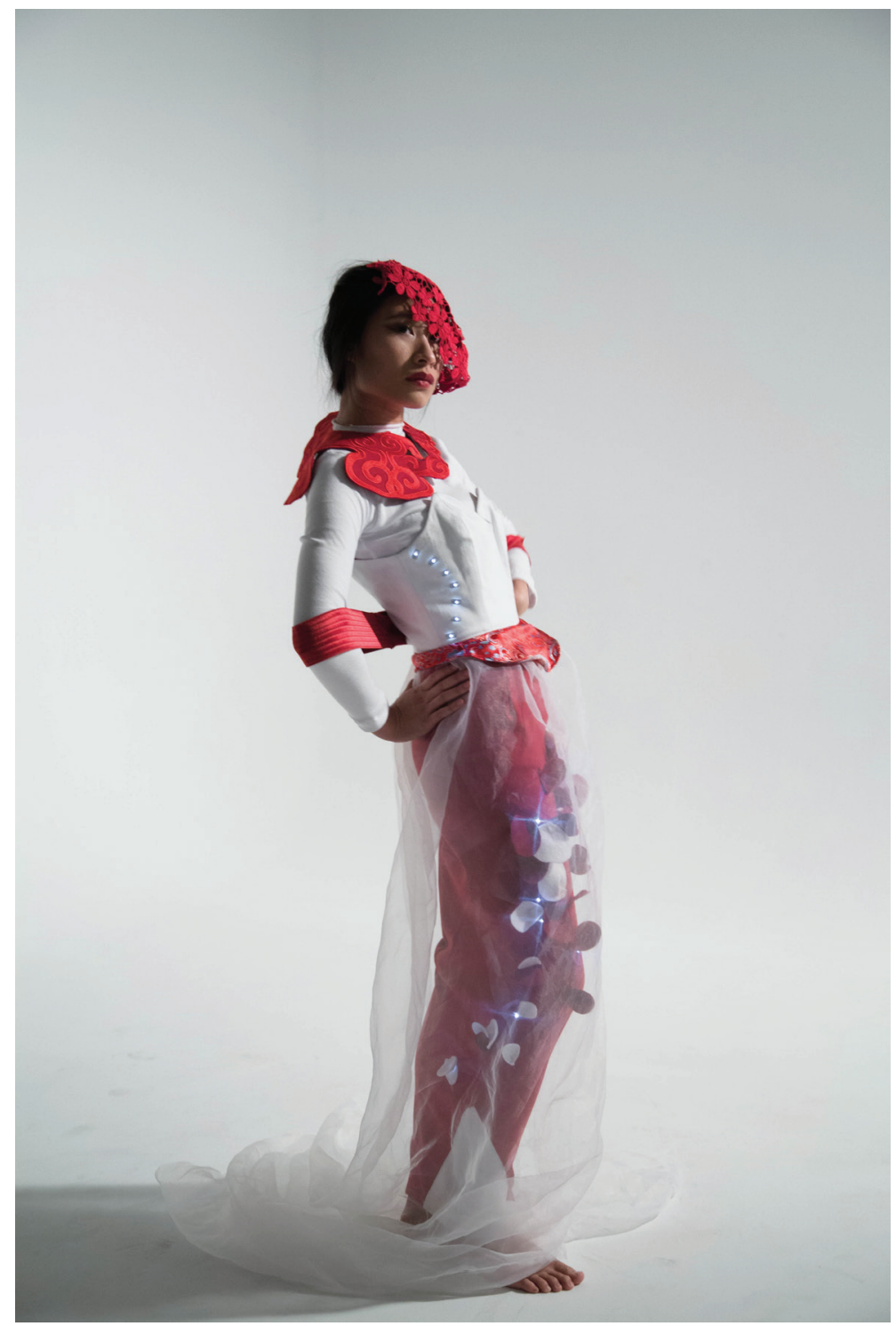

Figure 8.9 

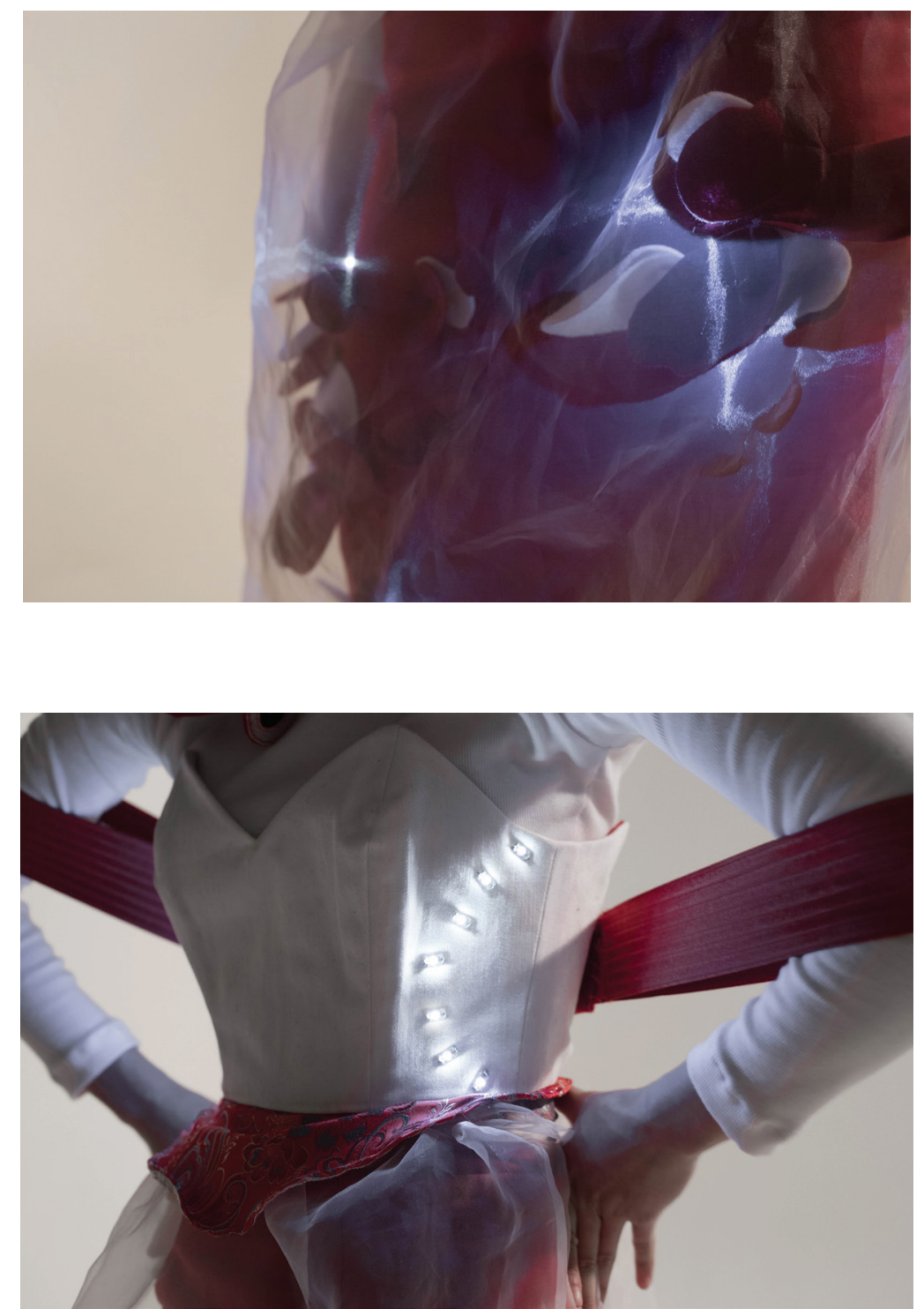

Figure 8.10 


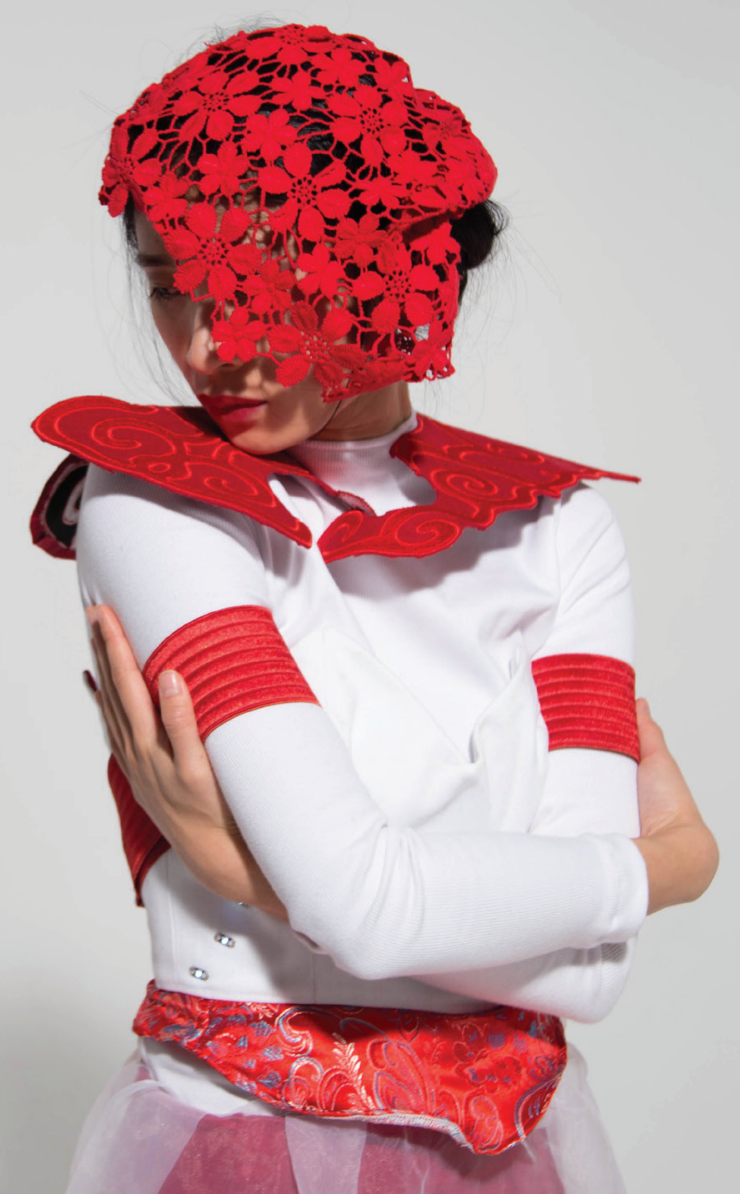

Figure 8.11 


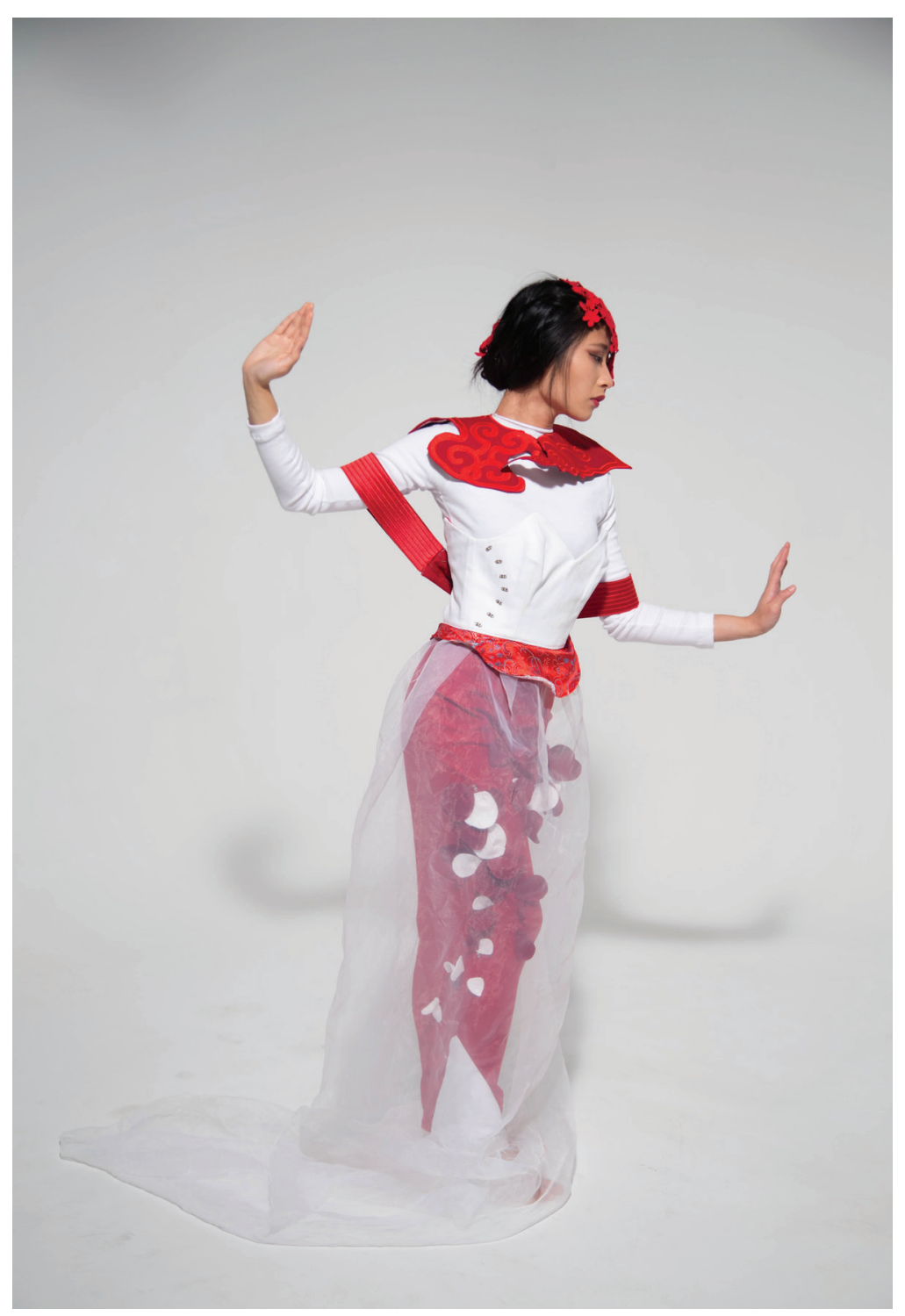

Figure 8.12 
9

Discussion \& Conclusion 
Zi.Force's design process reflects my personal view of Chinese women being constrained by marriage. The garment constrains the model's movement through the elastic and inelastic fabric. LEDs that flash when the audience approaches make viewers nervous.

Zi.Force is my final prototype. It combines art with technology. My design strategy is to use interactive wearables, to research Chinese marriage and its lack of freedom, and to raise awareness so that people can understand these issues through their experience. In the future, I plan to continue exploring wearable art and technology. I will improve usability, and build on the relationship between interactive wearables and Chinese culture.

Zi.Force contributes to the field of wearable art. This garment helps to fill a gap in Chinese feminism art. It discusses feminist issues in China using contemporary rather than traditional media. Zi.Force is informed by the restriction of traditional Chinese marriage and how that makes women feel. The garment draws attention to inequality and aims to make the audience think about traditional Chinese marriage and women's freedom.

\section{Zi.Force focuses on:}

1) Using a critical and contemporary way to express feminism

2) Using the model's movement and spatial experience with the audience to establish an interactive design

3) Combining traditional Chinese and Western wedding elements

4) integrating electronic elements to enhance the design

Zi.Force uses lights turn on to reflect the model's self-experience from the model opens her arms. By flashing lights on the petals to reflect the space from the audience. Zi.Force is the art of conveying a message which the Chinese women in 21st century who wants to freedom of marriage, and respect for people around us, not excessive criticism.

Zi.Force's final photos and video are available online:

(link: Video: https://vimeo.com/224792613 Photos: https://www.behance.net/gallery/54583143/ Zi-Force ) 
10 
Cao, H. (2013). Review and Introspection: Research of Chinese Feminist Art Form 2002 to 2011 [Abstract]. Study and Exploration. Retrieved from http://review.artintern.net/html.php?id=63409 Cao, J. (2013). The Self-Consciousness From The Contemporary Chinese Women Artist's SelfPortrait.

Chen, H. (1995). Contemporary Chinese Literature: Feminism • Literature feminine · Female . Literature and Art Criticism. Vol. 4.

Chen, H. (2016, April 8). Emotional advert about China’s 'leftover women' goes viral. Retrieved from BBC News: http://www.bbc.com/news/world-asia-china-35994366

Cheng, X. (2011). Pingjing de Yanshuo--- Zoujing Liu Manwen de yi shu shi jie. Kuart 201101, Volume 17. $84-85$

Davis, D., \& Harrell, S. (1993). Chinese families in the Post-Mao Era (Vol. 17). University of California Press.

Du, Q. (2016). Wo guo hun ying jia ting fa de chuan tong yu xian dai hua tan xi [Analysis from Traditional to Modern in Chinese Marriage Law]. Journal of Hubei University of Economics (Humanities and Social Sciences). Vol.13 No.1 107-108

Huang, Y. (1997). Zhongguo chuan tong she hui de fa lü yu fu nü di wei. Journal of Peking University (Humanities and Social Sciences), Vol. 3, 103-112.

Ho, J. (2016). Synaesthesia Playground. Retrieved from http://www.jocelynho.com/synaesthesiaplayground/

Ip, E., Lee, S., \& Schiphorst, T. (2014, June). The Wearable Self: Braiding a Feminist Critique within a Somaesthetics Framework for Design. In International Conference of Design, User Experience, and Usability (pp. 285-296). Springer, Cham.

Jia, F. (2003). Era of Criticism: Selected Works of Chinese Art Critics in the End of 20th Century. Guangxi Fine Art Publishing House

Jörg, H. \& Zhou, C. (2014). The Body at Stake: Experiments in Chinese Contemporary Art and Theatre. Ke, L. (2010). Analysis of Chinese Women's Family Status Changes and Causes in Modern Period. Journal of Fuqing Branch of FuJian Normal University. No. 100, 126-130

Kwon, Y. (2013). Pattern changing clothing. http://scholarworks.rit.edu/cgi/viewcontent. cgi?article $=6750 \&$ context $=$ theses

Lan, F. (2011). Cong hun yin fa de fa zhan kan Zhongguo nü xing di wei bian qian. Legal System and Society , 161-162.

Li, X. (2012). Feminist Research: Feminist Art Theory- "Feminine Art" and "Feminist Art". Retrieved from http://www.bald-girls.net/shownews.asp?id=33

Mang. (Oct., 2016). Chinese Text Project. (J. Legge, Trans.). Retrieved from: http://ctext.org.

N.d. (the Spring and Autumn period ). Guofeng.Wei Feng. Meng 
N.d. (the Warring States Period). Zhouyi, Xici.

Ni, J. (2006). Western Feminist Art and Women Art in Chinese Modern. Theory and Creation, 121-123.

Nie, X. (2003). Wu qiang “mai qi” liang qian “mai qi” nong cun mai mai hun yin cheng gu ji. Retrieved from NEWS.SOHU.COM: http://news.sohu.com/51/39/news209723951.shtml

Nochlin, L. (1989). Women, art, and power: and other essays (Vol. 183). Westview Press.

Ryan, S. E. (2008). What is wearable technology art. Intelligent Agent www. intelligentagent. com, 7-12.

Ryan, S. E. (2009). Social fabrics: wearable+ media+ interconnectivity. Leonardo, 42(2), 114-116.

Schneider, M. (2014). The Ugly Wife Is a Treasure at Home: True Stories of Love and Marriage in Communist China. University of Nebraska Press. Retrieved fromhttp://www.jstor.org/stable/j. ctt1d9nn9w.

Seymour, S. (2008). Fashionable Technology: The Intersection of Design, Fashion, Science, and Technology. New York: Springer, p. 12.

SK-II (Director). (2016). Single women over 27 in China are known as "leftover women" [Motion Picture].

Strong, A. L. (1984). Zhongguo ren zheng fu Zhongguo [The Chinese Conquer China]. Xin hua shu dian Beijing fa xing suo fa xing.

Studio Roosegaarde (2006-2012). DUNE. Retrieved from https://www.studioroosegaarde.net/ project/dune/info/

Studio Roosegaarde (2006-2012). Intimacy. Retrieved from https://www.studioroosegaarde.net/ project/intimacy-black/

Sun, Y. (2008). Lun Zhongguo fu nü hun yin de quan li pin kun: Modern China Studies- MCS 2008 Issue 3. Retrieved from: http://www.modernchinastudies.org/us/issues/past-issues/101-mcs2008-issue-3/1064-2012-01-05-15-35-31.html

Teng, Y. (2007). Nv Xing Zuo Wei Jie Kou: Nv Xing Zhu Yi Yi Shu De Ju Xian Xing. Oriental Art Finance. 80-86

Teresa, A. (2011). Euphoric Femme; an interactive media art installation exploring women's sexual subjectivity.

Wang, M. (2006). Review Art in Feminism in the World. All Eye Shot Retrieved from: http://www. alleyeshot.com/html/200607/28/20060728142015.htm

Wang, W. \& Liu, L. (2015). Awakening and Transcendence-- the Chinese feminist art at the true of century, Hubei Institute of Fine Arts Journal, 4-8.

Wang, X. (2012). Chinese feminism in 21st Century. Journal of Chongqing University of Science and Technology (Social Science Edition), 104-105.

Wu, X. \& Wang, M. (2011). A Brief Analysis on Contemporary Chinese Female Artists' Sexual 
Consciousnesses. Journal Of Hunan University Of Technology Social Science Edition. 97-99

Wu,C. \& Xia, Y. (2009) The Evolution of Chinese Marriage Law during the Period of Thirty Years' Reform and Opening up. Journal of China Women's University. 18-19

Xiong, X. \& Wang, Y. (2000) Self-determination, Self-knowledge, Self-examination, Self-support: New Exploration on the Connotation and Implication of Shiling, WeiFeng, Meng. Journal of Southwest China Normal University (Humanities and Social Sciences Edition). Vol.26 No.5. 140143

Xue, Y. (2010). “Nü xing yi shu de wen ti yu ying dui”. [Web log post]. Retrieved July 10, 2017, from http://blog.artintern.net/article/111637

Yan, G. \& Zhang, Y. (1999). "Ru jia fu nü guan yu xian dai zi nü jiao yu”. Journal of Adult Education College of Hebei University. No.4: 3-6.

Yi, Y (2006). The Primary Connotation of Chinese Traditional Ethics on Women [J]. Journal of China Women's University, Vol. 18 No. 3, 43-46

Yin, H., \& Huo, Z. (2010). “Fei cheng wu rao”: yu qing yu le. Modern Communication (Journal of Communication University of China), Vol. 5, 81-82.

Zhou, Q. (2005). Art in Feminism in the World. Jouzhou Press.

Zhou, X. (2010). Qian tan "Shijing, Weifeng, Mang” dui xian dai, hun yin he jia ting de qi shi [ On the Revelation of Modern Love, Marriage and Family in The Book of Songs]. Master Pieces Review. No. 6. 136-167

Zhu, X. (2014). Thoughts on Chinese Translation of "Feminism". China Terminology. Vol 16, No.1, 49-51,57 
Image References

All unlist figures belong to author

Figure 3.1: Studio Roosegaarde (2006-2012). Intimacy Black. Retrieved from https://www. studioroosegaarde.net/project/intimacy/photo/\#intimacy-black

Figure 3.2: Studio Roosegaarde (2006-2012). Intimacy White. Retrieved from https://www. studioroosegaarde.net/project/intimacy/photo/\#intimacy-white

Figure 3.3: Studio Roosegaarde (2006-2012). Intimacy2.0. Retrieved from https://www. studioroosegaarde.net/project/intimacy/photo/\#intimacy-2-0

Figure 3.4: Teresa, A. (2011). Euphoric Femme; an interactive media art installation exploring women's sexual subjectivity. Retrieved from http://www.velvetparkmedia.com/blogs/euphoricfemme-teresa-ascencao

Figure 3.5: Studio Roosegaarde (2006-2012). DUNE. Retrieved from https://www.

studioroosegaarde.net/project/dune/info/

Figure 3.6: Ho, J. (2016). Synaesthesia Playground. Retrieved from http://www.jocelynho.com/ synaesthesia-playground/

Figure 3.7: Ip, E., Lee, S., \& Schiphorst, T. (2014, June). The Wearable Self: Braiding a Feminist Critique within a Somaesthetics Framework for Design. Retrieved from https://wodefy.wordpress. com

Figure 5.9: Duong, N. (2013). Fashion timeline of Chinese Clothing. Retrieved from https://wodefy. wordpress.com

Figure 5.11: Duong, N. (2013). Fashion timeline of Chinese Clothing. Retrieved from https://wodefy. wordpress.com

Figure 5.13: Bu, R.(2016) Yun jian. Retrieved from https://kknews.cc/culture/qabvb.html Figure 5.14: n.d.(2011) Auspicious clouds. Retrieved from: http://www.nipic.com/ show/1/93/5216932kbeaeddfe.html 
